2013

\title{
TEACHING THE GAS PROPERTIES AND GAS LAWS: AN INQUIRY UNIT WITH ALTERNATIVE ASSESSMENT
}

Michael Hammar

Michigan Technological University

Follow this and additional works at: https://digitalcommons.mtu.edu/etds

Copyright 2013 Michael Hammar

\section{Recommended Citation}

Hammar, Michael, "TEACHING THE GAS PROPERTIES AND GAS LAWS: AN INQUIRY UNIT WITH

ALTERNATIVE ASSESSMENT", Master's report, Michigan Technological University, 2013.

https://doi.org/10.37099/mtu.dc.etds/698 


\title{
TEACHING THE GAS PROPERTIES AND GAS LAWS: AN INQUIRY UNIT WITH ALTERNATIVE ASSESSMENT
}

\author{
By \\ Michael Hammar \\ A REPORT \\ Submitted in partial fulfillment of the requirements for the degree of \\ MASTER OF SCIENCE \\ In Applied Science Education
}

MICHIGAN TECHNOLOGICAL UNIVERSITY

2013

(C) 2013 Michael Hammar 
This report has been approved in partial fulfillment of the requirements for a Degree of MASTER OF SCIENCE in Applied Science Education.

Department of Cognitive and Learning Sciences

Report Advisor: Shari L. Stockero

Committee Member: Kedmon N. Hungwe

Committee Member: Kris G. Mattila

Department Chair: Bradley H. Baltensperger 


\section{Table of Contents}

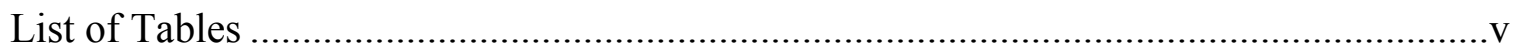

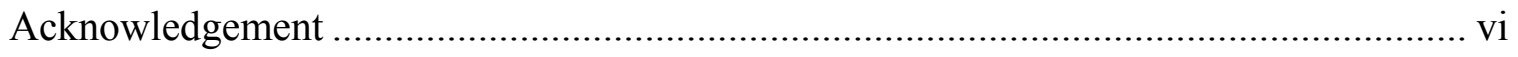

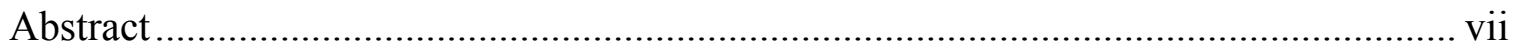

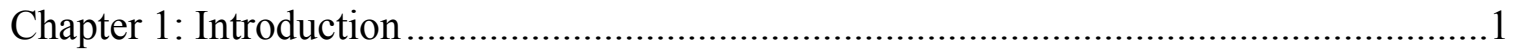

School and Classroom Context .............................................................................. 1

Instructional Paradigm within the Classroom.......................................................4

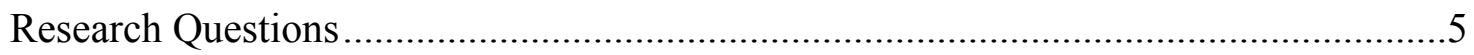

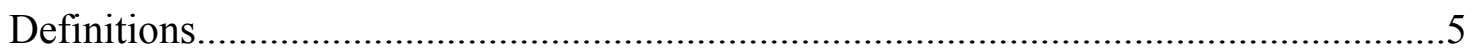

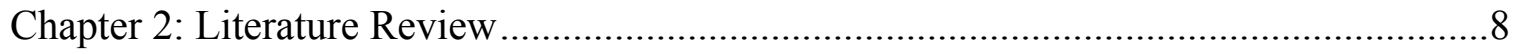

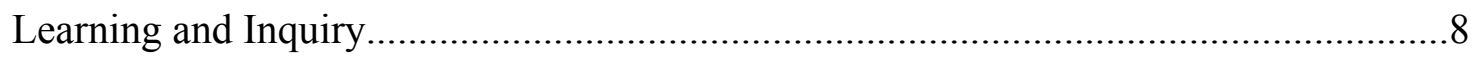

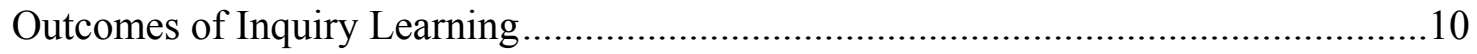

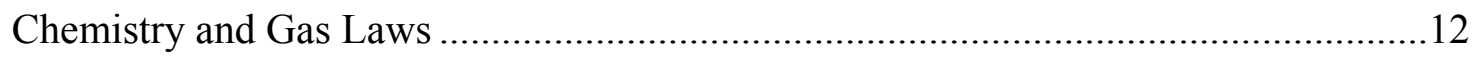

Inquiry and Performance Assessments ........................................................ 14

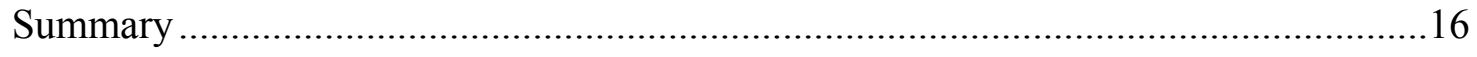

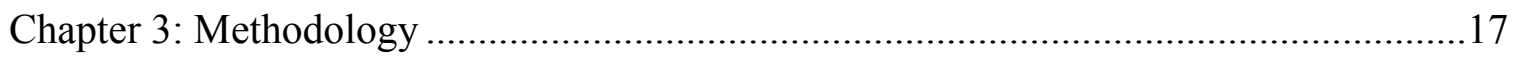

Experimental Class vs. Comparison Class........................................................ 17

The Unit Comparison........................................................................................ 18

Data Collection and Analysis............................................................................22

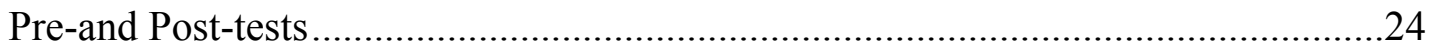

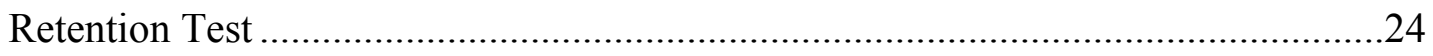


Student Survey

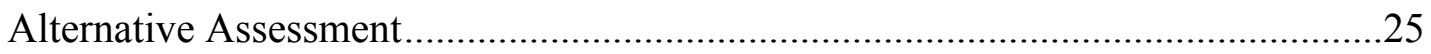

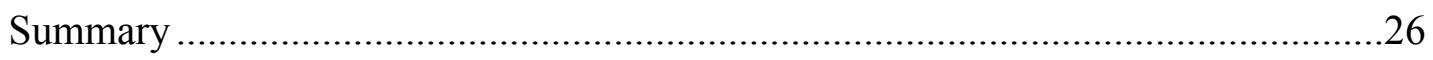

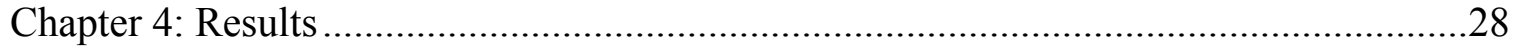

Academic Achievement of Comparison and Experimental Groups ..............................28

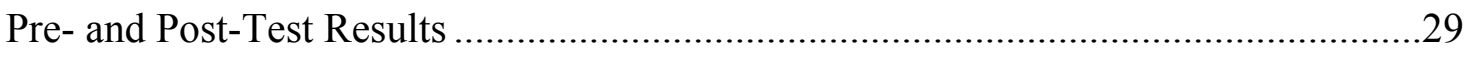

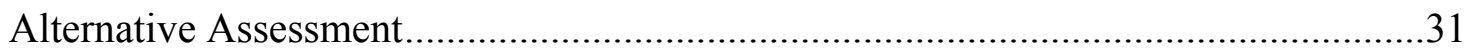

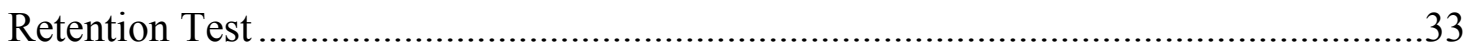

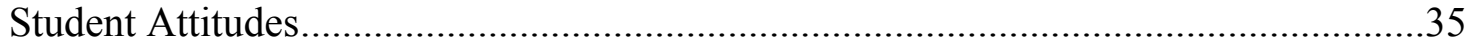

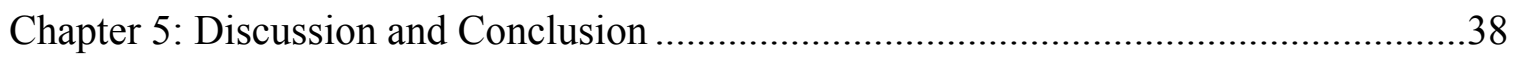

Research Question 1: Effects of Unit on Student Performance.......................................38

Research Question 2: Alternative Assessment Results................................................41

Research Question 3: Student Attitudes Toward Learning..........................................42

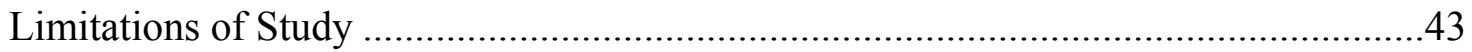

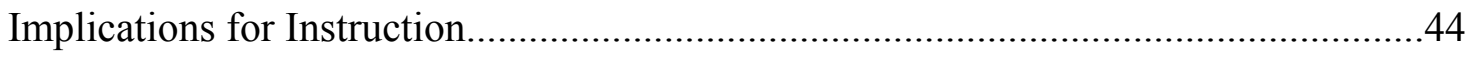

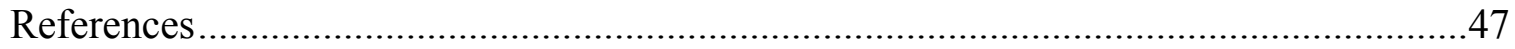

Appendix A — Lesson Plans for Gas Properties and Gas Law Unit..................................50

Appendix B - Alternative Assessment on Gas Pressure ……………..............................60

Appendix C - Pre- and Post-test on Gas Properties and Gas Law Unit ............................64

Appendix D—Retention Test on Gas Properties and Gas Laws ......................................69

Appendix E—Student Attitude Survey ......................................................................74 


\section{List of Tables}

Table 1: Summary of Gas Properties and Gas Law Unit Activities ...............................23

Table 2: Research Questions and Data Sources........................................................27

Table 3: Scoring Comparison between Experimental and Comparison Groups on

Alternative Assessment (by Sections and Requirements) ...........................................33

Table 4: Student Attitude Survey Results: Likert Scores for Gas Properties and Gas Law

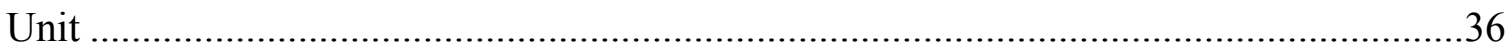




\section{Acknowledgements}

I would like to thank Shari Stockero for all of her assistance, time and patience on this project. I would like to thank my wife Tracy Hammar for her support during the course of this endeavor. 


\begin{abstract}
As a chemistry teacher I felt that the gas laws were rather simple concepts to understand. My students, however, felt the opposite. Conceptual issues, as well as mathematical issues were problematic every year. In this study, a unit about gas properties and gas laws was modified to include inquiry-based teaching methods. The research questions focused on how these changes affected student results on a traditional end-of-the-unit test and on an alternative assessment. Students' attitudes during these lessons were also monitored to see if the inquiry methods improved student perceptions of teaching, learning, and self-awareness. The results of this study showed that an inquiry approach improved the student's ability to perform on a traditional end of the unit test in the areas of microscopic understanding (atomic level), symbolic understanding (mathematical level) and graphical understanding (relationships between pressure, volume and temperature). It was also shown to a have a positive effect on the students' confidence and attitude towards the material presented when inquiry was utilized. On the other hand, the revised unit did not improve the students' overall performance on an alternative assessment geared towards the concept of pressure, but showed some improvement in two specific areas: (a) students' understanding that pressure is created by molecules and their movement and (b) students' understanding that when pressure is equalized little happens within a system.
\end{abstract}




\section{Chapter 1: Introduction}

According to the State of Michigan Science Benchmarks for Chemistry (Michigan Department of Education, 2006), gas laws are a crucial part of a student's chemistry education. As a chemist I found the gas laws easy to understand, but when it has come to teaching them to my students, I have found that they have a difficult time understanding some of the basic concepts of pressure, temperature and volume. Compounding the issue, is their struggle with the mathematics associated with gas law concepts. My previous teaching methods were not effective and the opportunities to do investigations within the gas law unit were very limited. This led to a low retention of gas law knowledge as seen on the year-end final exam. It was my hypothesis that if I modified my current instructional unit to give students a solid foundation grounded in the macro-scale observation of gases, they would begin to also understand the micro-scale theory and the mathematics (symbolic representations). My hope was that utilizing an inquiry-based teaching approach with alternate assessments would give my students a better understanding of this content and, consequently, they would also improve their performance on a traditional gas law test. I also hoped students' attitudes towards learning would improve.

\section{School and Classroom Context}

North Central Junior/Senior High School is a small rural school. The school district is split into two buildings in two neighboring towns. This is uncommon for most small schools in the Upper Peninsula of Michigan. This divide splits up the schools' resources allowing for little money to go into classroom programs. Any classroom and curriculum modifications need to be free. 
The enrollment at the time of the study was 187 students in grades 7 through 12 . Of those enrolled, the primary source of family income is farming and health care. In turn, we have a high percentage of students who qualify for free and reduced lunch at a rate of $65 \%$ (an indicator of poverty in a district). It is these dynamics that lead to a distinct learning climate in the school and my classroom.

School wide, we schedule our classes on the basis of trimesters, rather than semesters. Financially, we needed fewer teachers in the high school to do so. Academically, this type of scheduling allows teachers to devote 72 minutes of instructional time every day for any class. This increased daily time is beneficial when teaching chemistry and performing laboratory activities. The trimester schedule also limits the number of classes any student takes to five per trimester, rather than seven per quarter. Another benefit of the trimester schedule is that it allows students to repeat a first trimester course in the second trimester if they happen to fail, allowing those students to finish a course in the same academic year as their peers. It is through this type of scheduling that our district can offer all classes in the Michigan Merit Curriculum (MDE, 2006) and still provide electives to students. The drawback of this schedule is that it limits the number of contact days a teacher has with students to 120 days ( $2 / 3$ of a school year). With the limited number of contact days, each of our teachers needs to pack the day with required content.

Our building has a total of fifteen full and part time certified teachers, three of whom are members of the science department (one teaches two science classes and I teach one). There is limited time to meet as a department and work on curriculum and planning, so what is done in the classroom is at the discretion of the teacher. In 
chemistry, the Michigan Merit Course/Credit Requirements for Chemistry (Michigan Department of Education, 2006) and the Michigan High School Chemistry Priority Expectations (ISD/RESA/RESD Collaborative, 2010) are the standards that need to be taught. These standards are the ones that students are assessed on every March when the statewide Michigan Merit Exam is administered. The standards below were taught during the gas law unit in this study.

C1.1D Identify patterns in data and relate them to theoretical models.

C1.1E Describe a reason for a given conclusion using evidence from an investigation.

C2.2B Describe the various states of matter in terms of the motion and arrangement of the molecules (atoms) making up the substance.

C2.2c Explain changes in pressure, volume, and temperature for gases using the kinetic molecular model.

C4.5a Provide macroscopic examples, atomic and molecular explanations, and mathematical representations (graphs and equations) for the pressure-volume relationship in gases.

C4.5b Provide macroscopic examples, atomic and molecular explanations, and mathematical representations (graphs and equations) for the pressure-temperature relationship in gases.

C4.5c Provide macroscopic examples, atomic and molecular explanations, and mathematical representations (graphs and equations) for the temperature-volume relationship in gases. 
Hence it is these standards that dictate the material taught within the chemistry classroom, but how that material is taught is up to me.

\section{Instructional Paradigm within the Classroom}

Prior to this study, I taught chemistry in a more traditional format based on the chemistry standards. I felt it necessary to "cover" all of the standard that needed to be learned. A warm up problem was used to start off the hour. It usually reviewed content taught in previous lessons. Then homework was corrected, followed by notes and lecture on the new material. When mathematics was part of the lesson, several sample problems were done to show how the formula worked. The end of the hour was used to work on the following day's homework. This process was typically repeated daily. Laboratory work was usually of the "cookbook" kind, where the students needed to follow a defined procedure to get to an end result. In the first trimester lab activities were done one to two times a month. This was due to limited lab access because biology is taught in the only lab setting in our school at the same time. During the second trimester I have the students do labs once a week.

With this study, the intention was to break from this repetitive teacher-centered mode, with assessments being at the end of each unit, and create a more inquiry-based, student-centered atmosphere. With this in mind, the students would investigate the properties of gases and the gas laws, they would be involved in demonstrations that exhibit how pressure works, they would be assessed utilizing a simple lab activity, and they would have macro-scale examples from which to relate the micro-scale theories and mathematics. This study sought to determine whether these methods were more effective than those previously used. 


\section{Research Questions}

To understand whether this new teaching paradigm was effective, I focused my research on answering the following questions:

1. How does engaging in an inquiry-based learning experience affect student performance on a traditional end-of-the-unit test geared towards the assessing student understanding of the macroscopic and microscopic nature of gases and gas laws, as well as the graphical and symbolic relationships among the quantities involved?

2. How does engaging in an inquiry-based learning experience affect student performance on an alternative assessment geared towards the macroscopic and microscopic nature of gases?

3. How does engaging in an inquiry-based unit with an alternative assessment affect student attitudes toward learning?

\section{Definitions}

The following terms are used throughout this work, and are defined as follows.

1. Alternative Assessment: Any assessment that is not of the multiple-choice, matching, or true and false, paper-and-pencil formats. This type of assessment requires students to complete a task or demonstrate a performance in solving a problem (Doran, Chan, Tamir, \& Lendhardt, 2002).

2. Graphical representation: The representation of gas laws through graphical means (e.g., a graph that shows what happens to volume as pressure goes up).

3. Inquiry-Based Learning: "Intelligent problem solving" that involves students thinking through a problem or task (Shimizu, 1997, pg 4). 
4. Macroscopic representation: Demonstrations/experiments that can be seen with the naked eye to show how gases behave.

5. Michigan Merit Course/Credit Requirements for Chemistry: A document that places the chemistry standards for Michigan into a priority system. All standards are placed together into units with similar themes and ideas. Each standard is also given a priority and importance, so teachers can maximize student learning.

6. Michigan Merit Curriculum: The required course standards that Michigan students need to meet in order to receive a state certified high school diploma. It includes: 4 English credits $\left(9^{\text {th }}-12^{\text {th }}\right.$ grade), 4 mathematics credits (Algebra, Geometry, Algebra II, one math class senior year), 3 Science credits (Biology, Chemistry or Physics, one more), 3 Social Studies credits (US History, World History, Government \& Economics), 1 Fine Art credit, 1 Health and PE credit, and 2 Foreign Language credits.

7. Microscopic representation: Theory that involves the molecular and atomic level of gases and how they work

8. Qualitative: An observation or test that is noticed through the senses. Usually written in descriptive sentence form.

9. Quantitative: An observation or test that is measured or given a number. Usually written in numerical form and collected in data tables.

10. Student Performance: A measure of how a student does on an assessment, regardless of assessment type or grading format.

11. Symbolic representation: Any representation that involves equations and numerical values. 
12. Traditional Test(ing): Any assessment that includes multiple-choice, matching, or true and false questions, typically given in a paper-and-pencil format. Some essay questions that assess factual knowledge or higher level thinking may also be included. 


\section{Chapter 2: Literature Review}

\section{Learning and Inquiry}

Teaching includes the use of a diverse set of strategies and methods to present information to a group of students. Learning is hopefully the end result of that teaching, but often times there is a disconnect between these two entities. According to Seidel and Shavelson's (2007) meta-analysis of teaching effectiveness and theory, learning includes six key components. First, learning is regulative. Students need the opportunity to monitor and analyze their progress. Second, learning is goal directed. Students need an objective to reach, it may be student selected, teacher selected or a combination of each. Learning is evaluative. Students need an opportunity to see if achievement goals are being reached, and appropriate feedback needs to be given by the teacher. Learning is also social. Students need the opportunity to interact with each other. Learning is domain-specific. Activities should have a real world context and have the potential to extend beyond the classroom. Finally, learning is constructive. Students acquire new knowledge by applying it to previous experiences and knowledge. These six components are the essence of teaching and learning in the field of science education, and specifically, are the basis of inquiry-based learning. It is through providing opportunities for students to engage in learning that include these components that a connection between teaching and learning can be achieved in a science classroom.

The field of chemistry, as in all sciences, is expanding in content expectations, skill sets, and ideas. In this ever-changing landscape, it is important that students come out of high school with the skills to be lifelong learners, not just houses for random facts and isolated bits of information. As teachers, we have to balance these two worlds- 
content knowledge along with scientific skills — while carefully monitoring time constraints. So how does one create this balancing act and connect teaching with learning? According to Drayton and Faulk (2001), "Inquiry is not process vs. content, rather [it is] a way of learning content" (p. 25). It is through this approach that science teachers are trying to balance the vast expanse of science content, within the constraint of time, and connect the teaching of science content and skills to student learning for the ever-changing future.

Along with Drayton and Faulk (2001), Shimizu (1997), the Next Generation Science Standards (Achieve Inc., 2013), and Michigan High School Content Expectations (Michigan Department of Education, 2006) all highlight inquiry as an important process or method that consists of certain scientific practices or performances. The process/method begins with students questioning the observable world around them. Then through hypothesizing, an experiment is developed to collect data. The analysis of this data then reveals an answer to a scientific question or creates a new question to be answered. The final step is to communicate findings their through written or oral formats. The benefit of inquiry-based science is that it reflects the essence of being a scientist a never ending cycle of discovery and questioning. According to the National Science Education Standards (National Research Council, 1996), through inquiry "students establish connections between their current knowledge of science and the scientific knowledge found in many sources; they apply science content to new questions; they engage in problem solving, planning, decision making, and group discussions; and they experience assessments that are consistent with an active approach to learning" (p. 20). These are all skills necessary to be a scientist in today's world. 


\section{Outcomes of Inquiry Learning}

So how does engaging students in inquiry affect student performance and learning in the classroom? In a meta-analysis of inquiry-based teaching, Furtak, Seidel, Iverson and Briggs (2012) found that engaging in the inquiry process produced a large positive result in the areas of student performance and learning. The positive results were found in three specific situations. The first was when students engaged in the, "epistemic domain of inquiry" (Furtak, et al. 2012, p. 324), meaning that students analyzed and evaluated their data and procedure and produced explanations for a phenomena (higher order thinking skills). It also includes the ability to see how science is ever-changing. The second situation was when students engaged in a combination of three domains of inquiry-epistemic, procedural and social. This means students were still evaluating but they also followed a process, the scientific method (procedural), and interacted with their peers (social). The one thing that was missing in both situations was surprisingly the conceptual domain, which involves content and theories. The final situation that produced positive results was teacher-guided inquiry, not student-guided inquiry. While inquiry is a broad term for a process, it seems most people think of inquiry as very student directed. Student-guided inquiry is where students create and guide themselves through an investigation, with help from the teacher. In this type of inquiry the teacher is more of a facilitator and sounding board. In teacher-guided inquiry, the teacher creates a situation where the students still have to question, hypothesize, experiment, analyze data, and communicate results, but the situation is predetermined by the teacher and progress is closely monitored and guided by that teacher. In this type of situation, teachers lead students to understanding science concepts and formulate conclusions about the world 
around them through an inductive process. This inductive process is designed around experimentation first and theory production second (Shimizu, 1997).

When students are placed into environments where inquiry-based learning is being used, student learning processes change drastically. Students begin to create their own understandings of the world, utilize personal experiences, and often come up with ideas that are unexpected (Shimizu, 1997). Inquiry is more of an inductive process as compared to a deductive process for the students. Deductive activities are like "cookbook" labs. The students start with a theory or idea to test, then guided by a very directed set of instructions, the students collect some data to confirm the theory. Inquiry is more inductive because students observe something, develop their own hypotheses, and then develop tests to confirm or deny those hypotheses. Through this process students can make sense of what is happening so a theory can be developed or disproved. Inquiry requires "reflective assessments of the significance of the experiments" (p. 7) and for students to be involved in "intelligent problem solving" (p. 4). Inquiry activities do not only require students to be problem solvers, but also require students to think about their own thinking; that is, engage in metacognition.

Kipnis and Hofstein (2007), for example, studied $12^{\text {th }}$ grade students in Israel over a 2-year period. During this time the students were learning chemistry through an inquiry-based lab approach. The results of their study showed that students who do inquiry-based labs are given many more opportunities to be metacognitive thinkers throughout the inquiry experience. According to these researchers, metacognition occurred in instances where students were writing the research question, defining their own procedure and writing the summary of their conclusions. This idea of metacognition 
has similarities to the regulative and evaluative components that Seidel and Shavelson (2007) describe as essential for learning effectiveness, which suggests that this inquiry process might promote more independent learners in our ever-changing scientific landscape.

\section{Chemistry and Gas Laws}

In chemistry, there are three levels of understanding that students should have in order to conceptually explain a topic such as the gas laws (Roehrig \& Garrow, 2007). The first is the macroscopic level, which includes observable phenomena and processes. The second is the microscopic level, which pertains to the arrangement and motion of particles. The final is the symbolic level, which is the mathematics and chemical notations of a situation.

In numerous studies (e.g., Christopher, Dockter, Ortiz, Passmore, Robins, \& Smith, 2009; Kautz, Heron, Loverlude, \& McDermott,, 2005; Roehrig \& Garrow, 2007) students were found to perform well on decontextualized symbolic problems, but scores lowered as soon as conceptual knowledge was required to solve a problem. This is most likely due to chemistry teachers focusing primarily on the symbolic understanding when teaching the gas laws, rather than on the macroscopic and microscopic levels of understanding (Lin, Hsiu-ju, \& Lawrenz, 2000). A research study by Roehrig and Garrow (2007) suggests, however, that it is possible to remedy this problem. In their study, several teachers were followed while teachinig a gas laws unit. Their use of a new curriculum was monitored using instruments designed to assess reform-based instruction. This study determined that teachers who utilized reform-based teaching methods (defined as using macroscopic, microscopic, and symbolic forms of instruction with inquiry) had 
significantly higher student performance on a standardized test. Also, their students' scores were significantly higher on questions pertaining to the microscopic and macroscopic levels of understanding of the gas law concept.

When is comes to difficulties at the symbolic level, Christopher and associates (2009) found deficiencies in student work, specifically that "students had greater difficulty answering questions pertaining to units, variables, plug-in problems, and conceptual problems than they did answering those related to algebra" (p. 35). In other words, the students could correctly do algebra problems similar to gas law problems out of context, but when placed into the context of a gas law problem the students struggled with gas law variables and the units of measure. In another study, Schuttlefield, Kirk, Pienta, and Tang (2012) found that similar factors involved in a symbolic problem affected a students' ability to complete the problem—-label conversions for temperature, pressure or volume, numbers in scientific notation or not, or gas type (ideal, mixed, or unknown). The difference is that Schuttlefield and associates looked at the symbolic level of understanding from a memory load standpoint, while Christopher and associates looked at it from a student performance standpoint (in context).

In Schuttlefield and colleagues' (2012) research it was determined that involving five different factors in a problem had a minimal effect on student performance, but on problems that included six factors, student performance was drastically reduced. For example, if a student had a combined gas law problem that had numbers in decimals (factor 1), a conversion from $\mathrm{L}$ to $\mathrm{ml}$ (factor 2), a mixed gas in a cylinder (factor 3), and a conversion of two temperature to Kelvin (factors 4 and 5), this would be an acceptable workload for a student. If the problem then introduced one more factor, such as 
converting final pressure to torr, the students' accuracy in finding a solution decreased significantly. The three factors that were found to most significantly affect a students' ability to solve a gas law problem were number format (e.g., scientific notation), volume conversions (e.g., $\mathrm{mL}$ to $\mathrm{L}, \mathrm{or}_{\mathrm{cm}}^{3}$ to $\mathrm{L}$ ) and temperature conversions (e.g., Celsius to Kelvin, or Fahrenheit to Kelvin). These studies highlight that both the number of factors in gas law problems and contextual understanding of the problem play a role in students' ability to solve gas law problems.

Inquiry and Performance Assessments

According to Doran and colleagues (2002), current assessment practices often focus around disjointed facts, assessed through multiple choice, fill in the blank, true and false, and short essay tests. On these tests, students often express their factual knowledge about the subject. This format stems from the behaviorist approach to education where students are believed to learn through memorization of out-of-context facts, often from textbooks that decompose information into its parts. Students are then expected to make connections to the material on their own.

Inquiry is a shift towards more of a constructivist approach to learning. According to Doran et al. (2002), "the constructivist approach begins with a focus on what the students already know about the world around them and on their understanding of this world. Using this as a base, educators work to help students develop methods for further educating themselves about the world" (p. 3). With this type of shift in the understanding of how students learn, one must assess students differently as well. Performance assessment is a specific type of alternative assessment where "student(s) complete, demonstrate or perform a behavior of interest" (Haury, 1993, p. 3). This type 
of assessment can be done individually or in groups. Performance assessments can be of three types: skills tasks, investigations, or extended investigations. Skill tasks require students to perform within a "narrow domain of skills" (Doran et al., 2002, p. 20). Often these tasks are done in stations and require students to utilize scientific skills like measuring, analyzing data, working with equipment, and observation. Investigations are laboratory experiences where the students follow the scientific method or at least part of it. These investigations are often clearly linked by the teacher to the unit of study and are done in a day or two. Extended investigations still follow the scientific method but they may be done over many days within a unit of study. They allow for a more in depth assessment of understanding of a particular topic, due to the length of time involved in the activity (Doran et al., 2002). Experiments and investigations are direct extensions of the inquiry process. They both require students to follow the scientific method, and use metacognition to solve problems as they arise during the process.

Although performance assessments and inquiry-based learning seem to be a good fit for each other, the jury is still out in regards to the relationship between student learning and their performance on these types of assessments. According to Baker (1991), alternative assessments have two major issues associated with their validity. The first is what is being assessed - content knowledge, skills or both. This is related to the issue of how to make these types of assessments a reliable measurement of student learning. The second issue revolves around how the assessment results will be used and to what extent the assessment provides evidence of student learning. In Baker's analysis of multiple studies she found only moderate correlation between the results of a performance assessment and student understanding. Baker suggests that these results could be due to a 
discrepancy in performance task specifications (construction and grading) across studies, lack of experiences in the classroom that prepare a student to take such an assessment, or the validity problems that are created by the complexity of a creating and grading a performance task.

\section{Summary}

The literature suggests that utilizing the six components of learning, engaging students in inquiry-based learning and incorporating the different levels of understanding of gases (macroscopic, microscopic and symbolic) are necessary to help students understand science, and particularly gas laws. Inquiry requires students to engage in metacognition, which is thinking about their own thinking. Metacognition allows students to be able to develop more complete procedures, draw accurate conclusions, and fix problems as they arise in the inquiry process; these are important aspects of scientific learning. The research also suggests that engaging in inquiry produces better student understanding of the microscopic and macroscopic properties gases, which in turn leads to a conceptual understanding of gases and their properties. It is this conceptual understanding, along with memory load, that assist students in performing better on gas law problems which represent the symbolic understanding of gases. Utilizing an inquirybased unit that incorporates findings from the literature will help to support student understanding of this important chemistry concept. 


\section{Chapter 3: Methodology}

For years my chemistry students struggled with the concepts revolving around gases and their laws. The major stumbling block appeared to be the connection between the macro-scale observations with gases and the micro-scale workings of the molecules. They also struggled to connect the mathematics (symbolic representation) to what was observed. My hope was that utilizing an inquiry-based teaching approach and alternate assessments, my students would have opportunities to observe how gases behave (macroscopic relationship), synthesize what was happening to the molecules in order to explain these behaviors (microscopic relationship), and calculate the mathematics associated with gas laws (symbolic relationship). Ultimately, I hoped that they would perform better on a traditional test, as compared to the students in my previous classes, and their attitude towards learning science would be positive.

\section{Experimental Class vs. Comparison Class}

The experimental class in which the revised teaching and assessments methods were used was an introductory chemistry class that was taught during the 2011-2012 academic year. The comparison class was an introductory chemistry class taught during the prior year, 2010-2011. The demographics of both classes were similar. The experimental class consisted of 17 girls and 2 boys. This was a very disproportionately female class (89.5\%). Similarly, the comparison class was made up of 15 girls and 5 boys, still disproportionate at $75.0 \%$ female. The experimental class contained 18 juniors and 1 senior while the comparison class was 20 seniors and no juniors. 


\section{The Unit Comparison}

Previously, the first two lessons in the gas law unit were very teacher-centered and book driven. Students were lectured about the properties of gases and asked to read a portion of the chapter in the textbook, taking notes on it as they read. These notes were then used to discuss gases and how they work in the "real world." To combat the teacher-identified problems with this lecture setting, in the revised unit in this study, the students were given materials to perform their own experiment on gases. Each group wrote mini-experiments and collected data to investigate some properties of gases. For example, some students determined that gases have mass. They found the mass of an empty balloon, then filled it up with air and found the mass again. They did this for several balloons and found that every time the mass went up. Other students determined that gases can travel from one place to another. These students sprayed air freshener and timed how long it took to reach them a distance away. These are both examples of the properties of gases that were previously taught through lecture and reading. The results from individual groups were then shared with the class and a list of properties was created. These properties mirrored the properties in the book, minus a few that could not be determined with the materials present. The six major gas properties were then discussed and read about from the textbook.

The second lesson in the unit taught the students the concept of pressure. This lesson consisted of teacher-led inquiry demonstrations (all demonstrations presented are in the unit plan in Appendix A). The same demonstrations were performed both years. The difference was that is in the first year the demonstrations were done only asking, "Why did this happen?" Students would explain and then be questioned until the correct 
reasons were produced. During the study the same initial question was asked, but subsequent questions were also included; these geared back to the gas properties that were discovered the day before and an emphasis was placed on the macroscopic and microscopic representations of gases and why pressure is created.

After a discussion of gases and their properties and demonstrations on gases and pressure, both groups of students completed an alternative assessment on gases. On this alternative assessment, the students were asked to observe what was happening at different points of a fountain created by an Erlenmeyer flask, a stopper and a piece of glass tubing (see full assessment in Appendix B). The students needed to describe why a fountain did nothing when put together (before fountain), why it spurted water out when air was added through a tube (during fountain), and why the water slowed down and stopped (after fountain). They were also asked to hypothesize what would happen if the air above the water was heated (extension).

Although the goals of the alternate assessment and the general activities were the same for both groups, for the comparison group the directions were unclear and a lot of teacher guidance was need for students to complete the activity, so modifications were made for the experimental group. The general directions for creating a fountain did not change, but direct instructions were added so the students knew when to make their observations. In the first version of the assessment, the students were just asked to observe what was happening at the three stages of the fountain: before, during and after stopping. In the revised version of the assessment, the specific instances were pinpointed so the students knew what to explain and when to make their observations. For example, instead of the vague statement "During fountain", the prompt was changed to, 
"Observation \#2: When the water is spurting out". This change was to assist in getting more responses that accurately assessed student understanding related to the instructional goal. One extra assessment criteria was also added to the rubric: somewhere during an explanation for any part, either beginning, during, after, or extension, the student needed to mention that gases have mass (for the score comparison in the data section this item was removed so the scores were comparable).

Following the alternative assessment, an inquiry-based lab day was created to have students test the effects of pressure on volume and of temperature on volume. The students were asked to investigate how temperature relates to volume (Charles' Law) or how pressure relates to volume (Boyle's Law). They then had to create an experiment in which they could collect data to investigate these situations given a stoppered syringe. The difficulty for the students was creating an experiment where they could measure the effects of one variable on the other and then be able to graph it. When they were done collecting data and graphing, the results were shared with the class, including their graphs. From this information the students completed the statement: If temperature goes up then volume goes and if pressure goes up then volume goes . Each group was given one of these situations to test because there was only 72 minutes to complete the activity. The previous year I simply lectured on the relationships in Boyle's and Charles' Laws and then went straight into the mathematics behind it.

At the completion of the Boyle's and Charles' Law inquiry lesson, the mathematics for the combined gas law and the ideal gas law was introduced. The problems assigned and the style of teaching (lecture driven) were the same for both 
classes but the method taught to solve combined gas law problems was different. Emphasis was more on the process previous to the study, rather than the macroscopic relationship and graphical connections between pressure, volume, and temperature. For example, in prior years I would explain to students what quantity goes where in the dimensional analysis t-chart for each step of the process for each problem. With the revised unit, we focused more on understanding what was happening with pressure; for instance, whether it was increasing or decreasing. Then we discussed what effect the change in pressure would have on the quantity of interest, temperature or volume, asking whether it would it increase or decrease. This was done by referencing back to the macroscopic examples we had looked at during the Boyle's Law (pressure and volume relationship) and Charles' Law (volume and temperature relationship) experiments along with their graphical representations. Finally, we discussed how the pressure values would need to be placed into the t-chart to make the volume increase (fraction greater than one) or decrease (fraction less than one). For instance, if the temperature increased then the volume would also have to get larger. In this case, the volume needed to be multiplied by a number greater than one, as this will cause the numerical value for the volume to become a larger.

To teach the ideal gas law to both groups, a lecture style format was utilized. Emphasis was placed on unit conversion (i.e., Celsius to Kelvin (temperature), milliliters to liters (volume), torr to atmospheres (pressure), etc). This did not change for the unit in the study. Finally, there was the end of the unit test in both years. They were different tests but both were administered on the last day of the unit. 
To help in data collection for the study, some other major changes were made.

First, the assessment process included a pre-test and a post-test, with a retention test two weeks after the post-test. This assessment format allowed for prior knowledge to be determined, for changes in knowledge related to the unit of study to be assessed, and retention of the information to be revealed.

In summary, included in the lessons were two completely student-led inquiry days and one teacher-led inquiry day, rather than the more traditional lecture format that filled these days the previous year. Overarching the entire unit was an emphasis on the four levels of understanding of gases: macroscopic understanding (naked-eye), microscopic understanding (atoms and molecules), graphical connections, and symbolic understanding (mathematical formulas). The unit was designed to incorporate the ideas of inquiry and alternative assessment (see Appendix A for full lesson plans). In short, the lessons were sequenced as shown in Table 1. The table also indicates which representation(s) of the gas laws were used in each lesson and whether the lesson was new or modified from those used in prior years.

\section{Data Collection and Analysis}

According to the protocol of action research it is suggested that, when possible, three data sources be used to address every research question in order to triangulate the data (Mills, 2007). These sources are then compared and analyzed to determine if the instructional intervention was effective. This principle was adhered to whenever possible. In the following, each source of data used in the study and how each was analyzed are discussed. 


\section{Table 1}

Summary of Gas Properties and Gas Law Unit Activities

\begin{tabular}{|c|c|c|c|}
\hline Day & Activity & $\begin{array}{c}\text { Level of } \\
\text { Understanding }\end{array}$ & Changes to Instruction \\
\hline 1 & Administered pre-test & All three & $\begin{array}{l}\text { Pre-test on this unit had not previously } \\
\text { been given. This assessment gave me } \\
\text { insight into students' previous knowledge. }\end{array}$ \\
\hline 2 & $\begin{array}{l}\text { Mini-experiments } \\
\text { created by students to } \\
\text { determine properties of } \\
\text { gases }\end{array}$ & Macroscopic & $\begin{array}{l}\text { Students experimented with the gasses } \\
\text { and filled out a graphic organizer on the } \\
\text { properties of gases before they read the } \\
\text { section in the textbook. This provided an } \\
\text { opportunity to engage in inquiry. }\end{array}$ \\
\hline 3 & $\begin{array}{l}\text { Teacher-led inquiry } \\
\text { demonstrations on } \\
\text { pressure and its relation } \\
\text { to the gas properties. }\end{array}$ & $\begin{array}{l}\text { Macroscopic and } \\
\text { microscopic }\end{array}$ & $\begin{array}{l}\text { This lesson was similar in structure to } \\
\text { prior years, but the questions asked } \\
\text { probed more into the microscopic aspect } \\
\text { of the demonstrations. }\end{array}$ \\
\hline $3 a$ & $\begin{array}{l}\text { Discussion on } \\
\text { microscopic and } \\
\text { macroscopic } \\
\text { representations with } 15 \\
\text { students. }\end{array}$ & $\begin{array}{l}\text { Macroscopic and } \\
\text { microscopic }\end{array}$ & $\begin{array}{l}\text { Not discussed the previous year. Due to } \\
\text { numerous absences and other activities, } \\
\text { this day was placed in to the unit to help } \\
\text { students understand a question on the } \\
\text { pretest. }\end{array}$ \\
\hline 4 & $\begin{array}{l}\text { Alternative assessment } \\
\text { utilizing the properties of } \\
\text { gases and pressure, } \\
\text { learned in day } 3 \text {. }\end{array}$ & $\begin{array}{l}\text { Macroscopic and } \\
\text { microscopic }\end{array}$ & $\begin{array}{l}\text { Done the previous year, but modified the } \\
\text { answer document and instructions to } \\
\text { make it clearer. }\end{array}$ \\
\hline 5 & $\begin{array}{l}\text { Student designed } \\
\text { experiments on the } \\
\text { relationships between } \\
\text { pressure and volume, } \\
\text { and temperature and } \\
\text { volume. }\end{array}$ & $\begin{array}{l}\text { Macroscopic, } \\
\text { graphical and } \\
\text { symbolic }\end{array}$ & $\begin{array}{l}\text { New lesson that had students experiment } \\
\text { to find the relationship between pressure } \\
\text { and volume and temperature and volume. } \\
\text { They collected data and graphed it. }\end{array}$ \\
\hline 6 & $\begin{array}{l}\text { Teacher lecture and } \\
\text { discussion on the } \\
\text { mathematics of Boyles, } \\
\text { Charles, Gay-Lussacs' } \\
\text { gas laws and combined } \\
\text { laws. }\end{array}$ & $\begin{array}{l}\text { Graphical and } \\
\text { Symbolic }\end{array}$ & $\begin{array}{l}\text { Same method I used previously, but made } \\
\text { connections to previous activities and } \\
\text { representations more often. }\end{array}$ \\
\hline 7 & $\begin{array}{l}\text { Teacher lecture and } \\
\text { discussion on } \\
\text { mathematics of the Ideal } \\
\text { Gas Law. }\end{array}$ & Symbolic & $\begin{array}{l}\text { Same method I used previously, but made } \\
\text { connections to previous activities and } \\
\text { representations more often. }\end{array}$ \\
\hline 8 & Administered Post-test. & All three & $\begin{array}{l}\text { Different test than the previous year. } \\
\text { More aligned with standards. }\end{array}$ \\
\hline
\end{tabular}


Pre- and Post-Tests

A pre- and post-test was administered to measure students' knowledge of gases and ultimately their progress toward achieving the unit's learning goals as defined by the Michigan Chemistry Standards listed in Chapter 1 (see Appendix C for copy of pre- and post-test). These traditional tests were designed in a multiple choice, short answer, problem, and essay format. The tests were used to determine if the inquiry-based unit that included an alternative assessment improved student understanding of gases and gas laws. The pre- and post-test scores were analyzed using a paired t-test to determine whether the modified teaching strategies improved student understanding of gases and gas laws. A question analysis was also done to see whether there were changes in student performance on specific questions related to the macroscopic, microscopic, graphical, and symbolic understanding of gases and the gas laws from the pre-test to the post-test.

\section{Retention Test}

A second traditional test was administered two weeks after the conclusion of the unit to monitor student retention of major gas concepts and the associated mathematics in order to further assess the effectiveness of this new inquiry-based unit (see Appendix D). This test was also created based on the Chemistry Standards and Benchmarks for the state of Michigan outlined in chapter 1. This was a different test than the pre- and post-test and was the end-of-the-unit assessment given the previous year (2010-2011). The responses to questions on the retention test were compared to the responses on the unit assessment to determine what material was retained over the two-week period following the completion of the unit. 
Utilizing the same test during the previous and current school years also allowed for comparison of student learning outcomes between the two classes. Even though the test was the end-of-unit assessment for the comparison group and the retention test for the experimental, the data was compared using an unpaired t-test to determine whether the test results gave further insight into the effectiveness of the new unit. Prior to this analysis, an academic comparison of the two different classes - comparison (2010-2011) and experimental (2011-2012) — was done to determine whether the groups were similar and to ensure the variability in the test subjects was limited. Specifically, the results of these tests were compared to look for improved results from the previous year's class.

\section{Student Survey}

Throughout the unit, at the end of every day, a semantic differential attitude scale or a Likert scale survey was given to each student. It was designed to check students' attitudes towards learning in different lessons (see Appendix E). This survey data was used to gauge how the students responded to the different lessons, their attitudes towards what was being taught, and how it was being taught. The attitude survey was also administered during another unit that was lecture-based to determine whether students' attitudes changed during two units taught in two different ways. The data from each survey was looked at collectively to understand students' overall attitude towards each lesson. The results of specific questions were also analyzed.

\section{Alternative Assessment}

An alternative assessment was designed to gather additional data related to student understanding of gases and pressure. It was administered after the first two days of teaching in both years and scored using the same rubric (See Appendix B). Comparing 
these two years of alternative assessment data was done to provide some insight into the effectiveness of the inquiry unit and the students' understanding of gas property knowledge. The data was analyzed using an unpaired t-test to compare the overall results from both years. The assessment was rubric scored in sections, which allowed for the results associated with each section of the rubric to also be compared using an unpaired ttest. These sections were before fountain eruption, during fountain eruption, after fountain eruption and extension (heating air above water). These section scores were analyzed to see if the modification in lessons helped students to better understand the different phases of the fountain. Within these sections, each included three requirements that had to be addressed in students' description of the observations: gas particle motion above the water, pressure creation by gas particles above the water, and pressure differences that cause observation to happen. Comparisons among these requirements were again made using an unpaired t-test.

\section{Summary}

In summary, four different sources of data were used to address the three research questions, with multiple data sources used to triangulate the findings whenever possible. These are summarized in Table 2. 


\section{Table 2}

Research Questions and Data Sources

\begin{tabular}{|c|c|c|c|}
\hline Research Questions & Data Source 1 & Data Source 2 & Data Source 3 \\
\hline $\begin{array}{l}\text { How does engaging in an inquiry- } \\
\text { based learning experience affect } \\
\text { student performance on a } \\
\text { traditional end of the unit test } \\
\text { geared towards the macroscopic, } \\
\text { microscopic, graphical, and } \\
\text { symbolic nature of gases and gas } \\
\text { laws? }\end{array}$ & $\begin{array}{l}\text { Traditional } \\
\text { Pretest on Gases }\end{array}$ & $\begin{array}{l}\text { Traditional } \\
\text { Post-test on } \\
\text { gases }\end{array}$ & $\begin{array}{l}\text { Retention test } 2 \\
\text { weeks after unit }\end{array}$ \\
\hline $\begin{array}{l}\text { How does engaging in an inquiry- } \\
\text { based learning experience, affect } \\
\text { student performance on an } \\
\text { alternative assessment geared } \\
\text { towards the macroscopic and } \\
\text { microscopic nature of gases? }\end{array}$ & $\begin{array}{l}\text { Alternative } \\
\text { Assessment "In } \\
\text { your face" lab } \\
\text { quiz done in } 2011\end{array}$ & $\begin{array}{l}\text { Alternative } \\
\text { Assessment "In } \\
\text { your face" lab } \\
\text { quiz done in } \\
2012\end{array}$ & \\
\hline $\begin{array}{l}\text { How does engaging in an inquiry- } \\
\text { based unit with an alternative } \\
\text { assessments affect student } \\
\text { attitudes toward learning? }\end{array}$ & $\begin{array}{l}\text { Student Attitude } \\
\text { Survey done } \\
\text { during previous } \\
\text { unit }\end{array}$ & $\begin{array}{l}\text { Student attitude } \\
\text { Survey done } \\
\text { during gas law } \\
\text { unit }\end{array}$ & \\
\hline
\end{tabular}




\section{Chapter 4: Results}

During the gas law unit in this study, both expected and unexpected results occurred. These results were analyzed through a pre- and post-test analysis, a Likert scale analysis, and an alternative assessment analysis. First, however, a student analysis of the experimental group (2011-2012) to a comparison group (2010-2011) was done to determine whether the groups were comparable academically.

Academic Achievement of Comparison and Experimental Groups

Academically, the comparison and experimental classes had many similarities but the experimental group seemed to be stronger in test taking. The chemistry class average for the experimental class was $79.23 \%$, while the class average for the comparison class was $76.37 \%$, so both classes averaged a $\mathrm{C}$ or $\mathrm{C}+$. Performing an unpaired t-test on the average grades resulted in $p=0.487$. When breaking grades down into trimesters, the experimental class averaged $76.05 \%$ in the first trimester while the comparison class averaged $69.09 \%(\mathrm{p}=0.191)$. For the second trimester, the one that included the Gas Law Unit, the experimental group averaged $79.94 \%$, while the comparison was $78.95 \%$ $(p=0.685)$. All of these grade comparisons indicated no significant difference between the two classes at a 5\% confidence level.

On all tests given throughout the year, the experimental group outscored the comparison group with an average of $77.51 \%$, while the comparison group averaged 67.20\%. An unpaired t-test comparing test averages for each student for the entire year resulted in $\mathrm{p}<.0001$, indicating that the experimental group averaged better on tests than the comparison group at a $5 \%$ confidence level. In terms of homework, the two sections averaged $77.00 \%$ (comparison) and $80.10 \%$ (experimental); an unpaired t-test resulted in 
$\mathrm{p}=0.2584$, indicating that the difference was not statistically significant. Thus, the experimental students are apparently better test takers, but appear comparable in homework and overall academics to the comparison students.

\section{Pre- and Post-Test Results}

The pre-test and post-test were given nine school days apart, at the start and end of the unit. During that time there was an increase in every student's score, although some improved more than others. The average score on the 19 pre-tests was $31.06 \%$ (range: $14.08 \%$ to $43.66 \%$ ), with a standard deviation of $8.75 \%$. On the post-test, the average score was $70.87 \%$ (range: $19.72 \%$ to $90.14 \%$ ), with a standard deviation of $17.33 \%$. With these scores, students had an average increase of $39.80 \%$ from pre-test to post-test (range $5.95 \%$ to $59.15 \%$ ) with a standard deviation of $14.8 \%$. Using a paired ttest at a 5\% confidence interval, the scores were analyzed to determine whether the results were statistically significant. The difference was found to be statistically significant with $\mathrm{p}<.0001$. This suggests that the gas law unit had some effect on the students' performance on the post-test assessment, which was the same test as the pretest.

The post-test had groups of questions that dealt with the macroscopic, the microscopic, the graphical, and the symbolic understanding of gases. These groups of questions were analyzed individually to determine whether there were differences in student gains by representation. On questions that dealt with the macroscopic representations - representations seen by the naked eye — students averaged 2.37 questions correct on the pre-test and 2.63 correct on the post-test (three questions, three total points). These questions were multiple-choice questions that incorporated real-world 
situations about how pressure, volume and temperature make objects change. Due to only a slight improvement in scores and high scores to begin with, the gas law unit seems to have had very little effect on student knowledge of the macroscopic representation of gases (see Appendix C problems 13,14, or 15 for examples).

On the microscopic understanding questions - those pertaining to atoms and molecules - the students had to describe what happened to the gas molecules when pressure, temperature, and volume changed. There was one question of this type with three parts, worth 18 total points (see Appendix C question 19 for an example). On the pre-test, the students averaged 2.74 points out of 18 possible, with a standard deviation of 1.69 on these microscopic representation questions. By the post-test the average was 9.47 points out of 18 with a standard deviation of 2.89. Using a paired t-test the results were found to be statistically significant, with $\mathrm{p}<0.001$. This suggests that the gas law unit had a positive effect on student performance on questions dealing with the microscopic understanding of gases.

On graphical questions, the students had to pick the line on a graph that best showed the relationship between pressure and volume, volume and temperature, and pressure and temperature (three questions, three points total). At first the student averaged 0.74 points out of $3(\mathrm{SD}=0.87)$, while by the post-test the average was 2.63 out of $3(\mathrm{SD}=0.90)$. Again using a paired t-test the results were found to be statistically significant $(\mathrm{p}<0.001)$ at a $5 \%$ confidence level (See Appendix C, questions 16, 17, or 18 for examples).

Finally, the students had to solve a combined gas law problem and an ideal gas law problem, both symbolic representations of gases ( 2 questions, 14 points total). Both 
of these problems were scored utilizing a scoring guide where the student received 2 points for showing the work leading to the answer, 3 points for the answer, 1 point for the correct label, and 1 point for the correct significant digits in the answer. On the pretest, students averaged 0.43 out of 14 possible points $(S D=0.84)$ with no student getting the correct answer for either problem, which was expected. On the post-test the students' scores jumped to 9.91 out of $14(\mathrm{SD}=4.46)$; this is a jump of 9.48 points. Also 10 out of 19 students got the correct answer to the combined gas law problem and 13 out of 19 students got the correct answer to the ideal gas law problem on the post test, compared to no students getting either correct on the pretest. Students scored better on the ideal gas law problem compared to the combined gas law problem, scoring 5.45 out of 7 points and 4.58 out of 7 points, respectively. A paired t-test showed $p<0.001$ for both questions combined, which is statistically significant at the $5 \%$ confidence level.

\section{Alternative Assessment}

On the alternative assessment, the students were asked to observe what was happening at different points of a fountain created by an Erlenmeyer flask, a stopper and a piece of glass tubing (see full assessment in Appendix B). This assessment was given to both the experimental and comparison groups after the first two lessons. Recall that for the comparison group, lecture was the primary form of teaching in those first two lessons, while for the experimental group inquiry was the primary form of teaching. The average score for the experimental students on the entire alternative assessment was 6.9 out of 12 possible points $(\mathrm{SD}=1.4)$, and for the comparison students the average score was 6.25 out of $12(\mathrm{SD}=2.1)$ An unpaired t-test was performed, which showed $\mathrm{p}=0.762$. According to this probability the difference in scores on the alternative assessment was 
not statistically significant. This suggests the results of this assessment were not affected by the change in teaching style.

The entire assessment was sectioned off into four parts related to what happens before the fountain starts, during the fountain's eruption, after the fountain stops, and during heating of the air [extension question]. On the assessment rubric, each of the four sections had three requirements. Requirement 1 related to motion of the particles in the air above the water in the flask, Requirement 2 related to the pressure created by the molecules above water, and Requirement 3 related to a pressure difference created by the air in the flask above the water. Table 3 shows a comparison of the scores of both classes for each requirement of the rubric. Using an unpaired t-test, the results showed no statistical significance in the During, Stopping, or Extension section scores for each student. There was a statistical significance in the Before section scores though. The experimental group outperformed the comparison group in this section with scores of 2.1 out of 3 compared to 1.4 out of 3 , respectively, which was found to be significant at the $5 \%$ confidence level $(p=0.012)$. This suggests that the experimental students could better explain the observations for the fountains' initial lack of movement than their peers after experiencing the first two inquiry days of the unit. Another area in which the experimental group outperformed the comparison group was their individual average scores on Requirement 2 that dealt with understanding that pressure is created by molecules above the water $(\mathrm{p}=0.009)$. The experimental group scored an average of 0.7 out of 1 while the comparison group averaged a 0.6 out of 1 . Although the difference in averages is minor the total points was quite low. Again this suggests that the experimental group students could relate the pressure above the water to molecular 
movement better after the first two inquiry days than could their peers. Finally, the average scores for each student on Requirement 3 (observations related to pressure differences) was not statistically significant but it was close. The average on this requirement was 0.3 for the experimental group and 0.6 for the comparison group. An unpaired t test showed $\mathrm{p}=0.068$.

Table 3

Scoring Comparison between Experimental and Comparison Groups on Alternative Assessment (by Sections and Requirements)

\begin{tabular}{ccccc}
\hline & \multicolumn{3}{c}{$\begin{array}{c}\text { Rubric Requirement Average } \\
\text { (out of 1) }\end{array}$} & $\begin{array}{c}\text { Section } \\
\text { Averages } \\
\text { (out of 3) }\end{array}$ \\
\cline { 2 - 4 } Section of Assessment & 1 & 2 & 3 & \\
\hline Before Fountain Average & & & & \\
Experimental & 0.6 & 1 & 0.5 & 2.1 \\
Comparison & 0.3 & 0.8 & 0.3 & 1.4 \\
\hline During Fountain Average & & & & \\
Experimental & 0.8 & 1 & 0.3 & 2.1 \\
Comparison & 0.9 & 0.5 & 0.8 & 2.2 \\
\hline Stopping Fountain Average & & & & \\
Experimental & 0.3 & 0.3 & 0.2 & 0.8 \\
Comparison & 0.3 & 0.3 & 0.6 & 1.2 \\
\hline Extension Fountain Average & & & & \\
Experimental & 0.7 & 0.8 & 0.4 & 1.9 \\
Comparison & 0.5 & 0.6 & 0.5 & 1.6 \\
\hline Average for Requirement & & & & \\
2011-2012 & 0.5 & 0.7 & 0.3 & \\
2010-2011 & 0.5 & 0.6 & 0.6 & \\
\hline
\end{tabular}

\section{Retention Test}

The retention test given to the experimental group was the same test given to the comparison group as a final assessment for the unit on gases. The class average for the experimental group was $53.5 \%$ with a standard deviation of 20.1 , while the comparison group averaged $62.9 \%$ with a standard deviation of 23.3 . This test was utilized so a 
comparison could be made between the two different years even though they were used for different assessment purposes. The p-value for an unpaired t-test on the retention test overall score was $p=0.198$, which is above the $5 \%$ confidence level, suggesting that there was no statistical significance between the scores for the two groups. This suggests the revised gas law unit did not have an impact on the results of this test. These results could be affected by a difference in assessment timing, however. Recall that the experimental group took this test two weeks after the unit's completion.

In comparing each student's post-test to their own retention test score, the average difference in scores was found to be $-17.10 \%$ with a standard deviation of 16.20 . Of the students taking the retention test (two were absent on this day so no comparison was made), only two students outperformed their post-test score, while the remaining students dropped. This drop in scores was due to the two-week window that the students were not learning about gases and gas laws. A paired t-test comparing the post-test and retention test scores found $\mathrm{p}=0.0049$. This means that the two-week window between post-test and retention test resulted in a significant difference in student understanding of the unit content, suggesting that students did not retain their understanding of the unit content. As for students' understandings of the different representations of gases, the experimental group struggled with some key concepts two weeks after completing the unit. Symbolically, the students struggled with the mathematics in general but the combined gas law proved to be more troublesome than the ideal gas law. On the post-test the students averaged $70.60 \%$ on all symbolic questions $(65.29 \%$ on combined gas law problems and $75.86 \%$ on ideal gas law problems). On the retention test scores dropped significantly, averaging $35.00 \%$ ( $29.84 \%$ on combined gas law problems and $47.07 \%$ on 
ideal gas law problems). Because the tests were different and the questions were scored differently, the only comparison that can be made is a percent correct. On questions that dealt with microscopic understanding of gases the post-test results were $52.61 \%$ correct, while the retention test had a percentage correct of $62.74 \%$. This was a surprising jump in scores but it could be due to the type of question. The post-test was a short answer/essay type question where the retention test included a series of multiple-choice questions. The retention test did not have enough questions to check for understanding of the macroscopic representation (one question), and there were no graphical questions on the retention test. This is a limitation of the data collection, as a test developed prior to the research study was used.

\section{Student Attitudes}

During this unit there were four days that were heavily based on inquiry, and there were two days that were still lecture based. For each of these days, the students were given a Likert scale survey to fill out. The scale went from -3 (strongly disagree) to +3 (strongly agree) with 0 being neutral. Prior to this unit, the students filled out one survey during a heavily lecture-based day, which focused on mathematics. All lecture days in this gas law unit revolved around mathematics and calculations as well.

When comparing student attitudes during these times some interesting points emerge. The inquiry days had consistently higher ratings on the Likert scale, in every category. Table 4 shows a list of the key questions from the survey and the average Likert score over inquiry days, non-inquiry days and the non-unit day. 
Table 4

Student Attitude Survey Results: Likert Scores for Gas Properties and Gas Law Unit

\begin{tabular}{lccc}
\hline Question & $\begin{array}{c}\text { Inquiry Day } \\
\text { Average }\end{array}$ & $\begin{array}{c}\text { Non-inquiry Day } \\
\text { Average }\end{array}$ & $\begin{array}{c}\text { Non-unit } \\
\text { Average }\end{array}$ \\
\hline $\begin{array}{l}\text { I understand the material } \\
\text { we are learning today }\end{array}$ & 2.43 & 1.63 & 1.11 \\
$\begin{array}{l}\text { I could teach the material } \\
\text { I learned to someone else }\end{array}$ & 1.79 & 0.89 & -0.10 \\
$\begin{array}{l}\text { I thought the teacher } \\
\text { explained the } \\
\text { content/directions well } \\
\text { today }\end{array}$ & 2.50 & 1.99 & 1.66 \\
$\begin{array}{l}\text { I feel I could do well on } \\
\text { this material if given a } \\
\text { test today }\end{array}$ & 1.45 & 0.38 & 0.00 \\
$\begin{array}{l}\text { I feel I was prepared for } \\
\text { what I was taught today }\end{array}$ & 2.42 & 1.75 & 1.82 \\
$\begin{array}{l}\text { I enjoyed the lesson that } \\
\text { was taught today }\end{array}$ & 2.61 & & 0.16 \\
$\begin{array}{l}\text { I put my full effort into } \\
\text { what was taught to me } \\
\text { today }\end{array}$ & 2.73 & 2.16 & 1.82 \\
\hline
\end{tabular}

Along with the inquiry days having consistently higher Likert-scale ratings, some specific details did emerge. First of all the students believed they understood the material better on inquiry days compared to non-inquiry and non-unit days (2.43 vs 1.63 and 1.11 , respectively). Regardless of type of day, though, the students lacked confidence in knowing the material. Two questions hinted towards confidence-I could teach the material to someone else and I could take a test on the material. Scores for the inquiry, non-inquiry and non-unit days were $1.79,0.89$, and -0.10 , respectively, for teaching the 
material to someone else and $1.45,0.38$, and 0.00 , respectively, for taking a test on this material today. Although all these scores were lower than hoped, it can be seen that confidence was much lower on the non-inquiry days and the non-unit day. This could have something to do with all these days being heavily laced with mathematics content. Another noticeable trend was that for every type of day the highest score was in response to the statement, "I put my full effort into what was taught to me today" (scores of 2.73, 2.16 and 1.82), with the highest scores on the inquiry days. Students clearly believed they put more effort in on inquiry days compared to the others $(2.73$ is the highest score on the entire table). The students also felt the teacher explained the material somewhat well on every type of day. These scores were also some of the highest when compared to all questions for a given type of day (inquiry days 2.50 , non-inquiry days 1.99 , non-unit day 1.66). Finally, the students clearly enjoyed themselves more on the days where inquiry was done (2.61 vs 1.13 and 0.16$)$. 


\section{Chapter 5: Discussion and Conclusion}

The instructional unit in this study was designed to improve student understanding of gas properties and the associated gas laws. In this study the intention was to see how teaching with more inquiry-based strategies improved student understanding of gas topics as measured on a traditional test and their understanding of gas properties measured using an alternative assessment. The study also monitored student attitudes to see if using inquiry-based teaching strategies affected student perceptions of their learning.

\section{Research Question 1: Effects of Unit on Student Performance}

According to the pre- and post-test analysis, the gas law unit in this study did have a significant effect on student performance, with student scores increasing an average of about $40 \%$. It is difficult, however, to validate whether the students performed better because they were simply taught the material, no matter what the method, or if this specific method and unit of teaching caused the effect. To better understand this issue, it would have been helpful to administer the same end-of-the-unit test to the comparison group because they were taught more traditionally, so their results would have helped to shed some light on the particular effects of the unit developed for the study.

What does shed some light on the gas law unit and its possible effectiveness is the retention test results. Granted there was a sharp drop in scores from the post-test average of $70.60 \%$ to the retention test average of $53.5 \%$ for the experimental group, but when compared to the comparison group, the results can be seen in a different light. The average score on the retention test for the experimental group was $53.5 \%$, while for the comparison group the average on the same test given at the end of the unit was $62.9 \%$. A 
t-test showed there was no statistical significance between these test scores, so it is possible that the unit of study did help the students better understand gas laws. In other words, because the experimental group took the test two weeks after the conclusion of the unit, it would be expected that their scores would be somewhat lower than at the end of the unit. So the fact that the comparison and experimental groups' scores were not statistically significant suggests that the methods used in this study helped the experimental group learn and retain portions of the material at the same level, and possibly even better than, the comparison group. These results could also be due to the fact that over the year the experimental group statistically did better on any test regardless of content, but this cannot be determined with the data collected in this study.

When it came to the levels of understanding (macroscopic, microscopic, graphical and symbolic), the students in the study performed statistically better from pre- to posttest on microscopic, symbolic, and graphical type questions, but not on questions related to the macroscopic level of understanding. For the microscopic understanding, the students were better able to describe what happens to gas molecules when pressure, volume and temperature were changed, but still struggled to completely grasp the concepts because they only received slightly more than half of the points possible, on average, on the post-test. This result could be due to the associated test question being difficult to understand from the student's perspective, as it contained multiple parts, but is still a concern. On the retention test there were six multiple-choice questions that assessed microscopic understanding. This was the only area where the scores jumped from an average of $52.61 \%$ correct (post-test) to $62.74 \%$ correct (retention test), but as 
discussed previously, the jump in scores could have been due to the different format of the questions on the two assessments.

The second area where the students showed significant improvement from the pre-test to the post-test was the symbolic level of understanding (mathematical concepts). There were two related questions on the pre- and post-tests; one dealt with the combined gas law and the other with the ideal gas law. Recall that no students got either of the questions correct on the pre-test, while 10 out of 19 students got the combined gas law problem correct and the 13 out 19 students got the ideal gas law problem on the post-test, an increase that was shown to be statistically significant. Again the question arises of whether it just the material that was taught or the method by which it was taught.

When the experimental group's post-test score was compared to their retention test score, it was found that students still had a greater difficulty with the combined gas law problems compared to the ideal gas law problems. They also dropped from a $70.60 \%$ correct average (post-test) to $35.00 \%$ correct average (retention test). It must again be noted that the questions were not scored the same, so this drop in overall scores and the variation between combined and ideal gas law scores could be due to either conceptual misunderstandings or the nature of each type of problem. In order to do an ideal gas law problem, students need an understanding of each variable in the formula $(\mathrm{PV}=\mathrm{nRT})$, how to convert units, and how solve the problem algebraically. For the combined gas law the students need a graphical and macroscopic understanding of gases and they need to convert units. It is this application of gas properties and relationships that may trip the students up and lead to these discrepancies. This combined gas law problem had three factors (two temperature conversions, and choice of gas ideal or combined) that 
contributed to the memory load of the problem; this is well below the given factor limit for success according to Schuttlefield, et al. (2012). As for the ideal gas law problem, there were only two factors (temperature conversion, and choice of ideal or combined) that contributed to the memory load. Clearly there was less complexity to the ideal gas law problem, which could have also attributed to the higher scores.

The scores on graphical questions also showed a significant increase from pretest to post-test, following a student-led inquiry lab on Boyle's and Charles' law and lessons in which the mathematics of these relationships was utilized. Again the retention test did not have any questions relating to the graphical nature of gases so no comparison could be made between the post- and retention tests.

\section{Research Question 2: Alternative Assessment Results}

On the alternative assessment there was no statistically significant difference found between the results from the experimental and the comparison group. In certain areas, though, some differences could be seen. The first thing the experimental students outperformed the comparison students in was explaining why the fountain does nothing in the beginning. After two days of student and teacher-led inquiry lessons, the experimental group of students were better able to identify that air molecules being in motion above the water creates pressure, describe how air molecules filled the space above the water, and notice that the pressure above water is slightly greater than that above the straw so water will rise slightly into the straw. These ideas were extensively discussed during the teacher-led inquiry demonstrations on Day 2 of the lesson plan, which likely led to a stronger understanding of these concepts. The second thing the experimental students were able to identify better than the comparison students was that 
pressure is created by molecules in motion above the water. Again these ideas of pressure and molecules were taught during the pressure demonstrations on Day 2. On the whole, though, the teacher and student-led inquiry days seemed to have had little effect on the overall results of the alternative assessment.

\section{Research Question 3: Student Attitudes toward Learning}

In terms of attitude, the students definitely preferred the inquiry-based days compared to the non-inquiry-based days. Every day that was inquiry-based had a higher Likert score on all 10 survey questions. It must be noted that every non-inquiry day, including those that were not part of the unit, did have a mathematical emphasis, which may have affected student attitudes. This is one thing that should be modified in this study to truly see if the scores are indicative of better attitudes on inquiry days or whether is it simply that days with a mathematical emphasis result in lower attitude scores.

Based on all of the Likert scale data, some interesting trends could be seen. First of all, student confidence about what was taught, as evident by their willingness to teach the material to someone else and their willingness to take a test on it, was much higher on inquiry days than on non-inquiry days. Again that confidence difference could be attributed to a lack of confidence in mathematical abilities on these non-inquiry days. On inquiry days the student very clearly reported putting forth the most effort and enjoying themselves more. There was also some indication that students felt the material was presented better on the inquiry days, but these scores were the closest of any set of scores regardless of type of day. Taken together, the data suggests that in the mind of the students, the inquiry days were perceived as better than the non-inquiry and than the nonunit days. The one thing that should be modified in terms of student attitude data is that 
more non-unit days should be tested and not all of them should be mathematics related. That way it could be seen if the Likert scores were truly higher on inquiry-based instructional days.

\section{Limitations of the Study}

There definitely were some issues that should be addressed if this study was to be replicated. The first issue is that all tests given to the comparison and experimental groups should be identical, so that direct connections between the learning outcomes of the two groups could clearly be made. In this study the pre- and post-test given to the experimental was not the same test given to the comparison group because the study was designed around a comparison group that was taught the unit before the study was created. This group was utilized because the school size is small, allowing for only one section of each class, and several pieces of data were collected from this group prior to the project that seemed to be useful. It would also aid in the analysis if the tests contained a set amount of questions related to each level of understanding (macroscopic, microscopic, symbolic, and graphical) so comparisons could be made across these levels. Specifically on the post-test, I would modify the question that dealt with the microscopic understanding, since in hindsight it seemed very ambiguous and confusing, possibly affecting its validity in assessing student learning. Also on the post-test, I would change the combined gas law problem to contain one volume unit conversion and one pressure conversion, a number of factors that are near the maximum recommended memory load of five factors (Schuttlefield, et al., 2012). 
As previously discussed, Likert surveys given on non-unit days should be administered on more days that do not involve mathematics, because mathematics oftentimes makes students uneasy and could account for lower attitudes on these days.

Implications for Instruction

As teachers, we are always trying to find better ways for our students to learn and retain material that is taught to them. Specifically, the results of this study suggest that several pieces of the unit should be modified. First of all, the overall low scores on the symbolic questions and the significant drop on the retention test on these types of questions suggest that more time should be spent connecting the relationships between pressure and volume and temperature and volume in all levels of understanding. More time might also be utilized to clarify the connection between the symbolic and macroscopic levels of understandings of gases in relation to the combined gas law and the ideal gas law. That way, the students might be able to better visualize the relationship between two quantities (pressure, volume or temperature) while performing the mathematical calculations, and in turn, perform the correct mathematical operations. Hopefully, this would lead to improved retention of these mathematical skills on the retention test.

Because the experimental group performed just as well as the comparison group on the alternative assessment, it seems that the modified inquiry days at the start of the unit had little effect on students' ability to explain what they were observing on this assessment. Thus, I plan to focus more on observational skills and drawing conclusions during the teacher-led inquiry day, so when the students perform the alternative assessment they will hopefully see more details and draw more realistic conclusions from 
those observations. Maybe focusing on these skills will improve the students' ability to take this type of assessment and perform better. According to Baker (1991) one possible factor for little correlation between student performance and the results of alternative assessment was a lack of coaching given to students on how to take this type of assessment. So maybe if I teach these skills, they will have more skills to perform better on this type of assessment. Also if these types of activities are done more regularly, then students will, hopefully, have the skills necessary to perform better on these types of assessments.

I would also like to find a way to make the mathematical days more engaging. According to the survey scores, for the mathematical days the students' interest, participation, and effort were all lower, meaning that the students were not engaged and ultimately not retaining as much information as they were on other days. One possibility is to try to reference or show more demonstrations of contained gases undergoing changes like a drop in temperature or increase in pressure while we do the mathematical problems. This might help students visualize the situation and make connections between the mathematics and what they are seeing. In general, making reference to different levels of understanding more often might help students connect the mathematics to something more tangible. It is this connected knowledge that we as teacher would like our students to develop.

Although time is always a factor in the classroom, possibly more days could be added to the nine-day unit to delve into concepts more deeply, specifically on the microscopic and symbolic level of understanding where students seemed to struggle the most. During this time, more connections could be made between the microscopic and 
symbol levels of understanding and the student's macroscopic understanding. Due to our trimester schedule only one or two days would be possible, however.

Ultimately, what I have learned from this study will hopefully allow me to

continue to change my teaching so that my students will have a better grasp of gases and gas laws, and a deeper understanding of the workings of science overall. The gas properties and gas law topics are challenging for students and I need to be more patient with them as we study these concepts in the future. 


\section{References}

Achieve, Inc. (2013). Next Generation Science Standards (Appendix F: Science and Engineering Practices in the NGSS). Retrieved from http://www.nextgenscience.org/sites/ngss/files/Appendix $\% 20 \mathrm{~F} \% 20 \% 20$ Science $\%$ 20and $\% 20$ Engineering $\% 20$ Practices $\% 20 \mathrm{in} \% 20$ the $\% 20$ NGSS $\% 20$ \%20FINAL \%20060513.pdf.

Baker, E. (1991). What probably works in alternative assessment. Los Angeles: National Center for Research on Evaluation, Standards and Student Testing.

Christopher, E., Dockter, D., Ortiz, C., Passmore, C., Robins, L., \& Smith, M. H. (2009). Teacher research: Challenging our assumptions: An investigation into student understanding of the gas laws. The Science Teacher, 76(6), 35.

Doran, R., Chan, F., Tamir, P., \& Lenhardt, C. (2002). Science Educator's Guide to Laboratory Assessment. Arlington, VA: National Science Teachers Association.

Drayton, B. \& Faulk, J. (2001). Tell tale signs of inquiry oriented classroom. NASSP Bulletin, 25, 24-34. DOI: 10.1177/019263650108562304

Furtak, E. M, Seidel, T., Iverson, H., Briggs, D. C. (2012). Experimental and quasiexperimental study of inquiry-based science teaching: A meta-analysis. Review of Educational Research 2012, 82, 300-329. DOI: 10.3102/0034654312457206.

Haury, D. L. (1993). Assessing student performance in science. ERIC Clearinghouse for Science, Mathematics and Environmental Education, ED359068. Retrieved from: http://www.eric.ed.gov. 
ISD/RESA/RESD Collaborative (2010). High school science priority expectations document: Chemistry priority expectations. Retrieved from:

http://www.resa.net/curriculum/curriculum/science/curriculum/priorityexpectation s/

Kautz, C. H., Heron P. R. L, Loverude M. E, \& McDermott L. C. (2005). Student understanding of the ideal gas law, part I: A macroscopic perspective. American Journal of Physics, 73(11), 1055-1063.

Kipnis M. \& Hofstein A. (2007). The inquiry laboratory as a source for development of metacognitive skills, International. Journal of Science and Mathematics Education, 6, 601-627.

Lin, H., Hsiu-ju C., \& Lawrenz, L. (2000). The assessment of students' and teachers' understanding of gas laws. Journal of Chemical Education 77(2): 235-238.

Michigan Department of Education. (2006) High school content expectations: Chemistry. Lansing, MI: Michigan Department of Education. Received from http://www.michigan.gov/mde/0,1607,7-140-38924_41644_42814---,00.html

Mills, G. E. (2007). Action Research: A Guide for the teacher researcher. Upper Saddle River, New Jersey: Pearson.

National Research Council. (1996). National science education standards.

Washington, D.C.: U.S. National Academy Press.

Roehrig, G. \& Garrow, S. (2007): The impact of teacher classroom practices on student achievement during the implementation of a reform-based chemistry curriculum, International Journal of Science Education, 29(14), 1789-1811. 
Schuttlefield, J. D., Kirk, J., Pienta, N. J., \& Tang, H. (2012). Investigating the effect of complexity factors on gas law problems. Journal of Chemical Education, 89, 586591.

Seidel, T. \& Shavelson, R. J. (2007). Teaching effectiveness research in the past decade: The role of theory and research design in disentangling meta-analysis results. Review of Educational Research, 77, 454-499. DOI: 10.3102/0034654307310317

Shimizu, K. (1997). Teacher emphasis on inquiry science and prevailing instructional methods. Presented at the Annual Meeting of the National Association for Research in Science Teaching. (ERIC Document Reproduction Service No. ED405213) 


\section{Appendix A: Lesson Plans for Gas Properties and Gas Law Unit}

\section{Day 1 Lesson: Pretest Gases}

Objective: To discover what students know about gases before we begin our unit on gases

\section{Benchmarks:}

C1.1D Identify patterns in data and relate them to theoretical models.

C1.1E Describe a reason for a given conclusion using evidence from an investigation.

C2.2B Describe the various states of matter in terms of the motion and arrangement of the molecules (atoms) making up the substance.

C2.2c Explain changes in pressure, volume, and temperature for gases using the kinetic molecular model.

C4.5a Provide macroscopic examples, atomic and molecular explanations, and mathematical representations (graphs and equations) for the pressure-volume relationship in gases.

C4.5b Provide macroscopic examples, atomic and molecular explanations, and mathematical representations (graphs and equations) for the pressure-temperature relationship in gases.

C4.5c Provide macroscopic examples, atomic and molecular explanations, and mathematical representations (graphs and equations) for the temperature-volume relationship in gases.

\section{Materials: Pretest on Gases}

\section{Lesson:}

1. Administer Pretest on Gases.

2. Grade Pretest on gases and utilize information to help in preparing for the remainder of the gases inquiry unit.

\section{Assignment: None}

Outcomes: To determine what the students know and do not know about gases. Utilize this information when setting up the gas law inquiry unit.

\section{Day 2 Lesson: Mini-experiments with Gases}

Objective: The students will learn about properties of gases by creating miniexperiments, using supplies provided by the teacher. They will collect 3 pieces of numerical data and/or evidence that supports their claims. The results will be presented to the class. A discussion of the data's validity will occur at this point. 


\section{Benchmarks:}

C1.1D Identify patterns in data and relate them to theoretical models.

C1.1E Describe a reason for a given conclusion using evidence from an investigation.

Materials: balloons, syringes, electronic balance, air freshener, string, graduated cylinder.

\begin{tabular}{|l|l|}
\hline Gas Properties & Kinetic Molecular Theory Postulates \\
\hline Gases have mass. & $\begin{array}{l}\text { Gases consist of small particles that have } \\
\text { mass }\end{array}$ \\
\hline Gases fill their containers. & $\begin{array}{l}\text { Gas particles have elastic collisions with } \\
\text { each other and their containers. }\end{array}$ \\
\hline Gases are compressible & $\begin{array}{l}\text { Gasses consist of particles that are } \\
\text { separated by relatively large distances }\end{array}$ \\
\hline $\begin{array}{l}\text { Gases can move through each other } \\
\text { rapidly }\end{array}$ & $\begin{array}{l}\text { Gas Particles move in random rapid } \\
\text { straight line motion }\end{array}$ \\
\hline Gases exert pressure & $\begin{array}{l}\text { Gas particle exert no attractive force on } \\
\text { each other }\end{array}$ \\
\hline $\begin{array}{l}\text { Pressure of gases depends on } \\
\text { temperature }\end{array}$ & $\begin{array}{l}\text { Gas particles kinetic energy depends on } \\
\text { temperature }\end{array}$ \\
\hline
\end{tabular}

\section{Lesson:}

1. Place supplies on a centrally located table. Students can grab what is needed as they need them.

2. Introduce the lessons objective. Make sure students understand that the evidence must be measurable and 3 data points must be collected.

3. Let the students work on collecting information about the properties of gases. They create there own mini-experiments and collect their own data. The supplies are very limited so the properties they can discover will hopefully be close to the list above.

4. Using poster board or large sheets of paper, have students write out their conclusions and the data that supports that conclusion. When time is up have them present their conclusions and findings to the entire class.

5. Discuss if their conclusions are supported by the data they collected.

6. Make a class list of verified properties of gases.

Assignment: Read pg 417 to 423 from "Chemistry Connections to Our Changing World" published by Prentice Hall, and worksheet (see next two pages). Fill in the two tables on Properties of Gases and Kinetic Molecular Theory Postulates of Gases. Write a paragraph comparing the similarities and differences between the two sets.

Outcomes: To have students understand the basic properties of gases, effective experiments on a small scale, and discuss validity of those experiments. Chemistry Gas Law Unit 
Day 2: Mini-experiments on Gases

Homework Assignment

Directions:

1. Read the section entitled, "13-1 A Model to Explain Gas Behavior" pg 417 to 423.

2. Complete the tables below.

\begin{tabular}{|l|l|}
\hline Property & Description \\
\hline & \\
\hline & \\
\hline & \\
\hline & \\
\hline & \\
\hline &
\end{tabular}

\begin{tabular}{|l|l|}
\hline $\begin{array}{l}\text { Kinetic Molecular } \\
\text { Theory Postulate }\end{array}$ & Description \\
\hline & \\
\hline & \\
\hline & \\
\hline & \\
\hline & \\
\hline
\end{tabular}

What are the similarities and differences between the gas properties and the Kinetic Molecular Theory Postulates? Formulate a paragraph comparing and contrasting the two.

\section{Day 3 Lesson: Teacher-led Inquiry Demonstrations on Pressure}

Objective: The students will utilize the properties of gases and Kinetic Molecular Theory to describe why certain events happen.

\section{Benchmarks:}

C1.1D Identify patterns in data and relate them to theoretical models.

C1.1E Describe a reason for a given conclusion using evidence from an investigation.

C2.2c Explain changes in pressure, volume, and temperature for gases using the kinetic molecular model. 
Materials: Meter Stick and newspaper, stoppered syringe, smooth rimmed cup, water, note card, large garbage bag (student can fit in with head out of top), Shop-Vac, hot plate, $1000 \mathrm{ml}$ beaker, aluminum can, and beaker tongs.

\begin{tabular}{|l|l|}
\hline Gas Properties & Kinetic Molecular Theory Postulates \\
\hline Gases have mass. & $\begin{array}{l}\text { Gases consist of small particles that have } \\
\text { mass }\end{array}$ \\
\hline Gases fill their containers. & $\begin{array}{l}\text { Gas particles have elastic collisions with } \\
\text { each other and their containers. }\end{array}$ \\
\hline Gases are compressible & $\begin{array}{l}\text { Gasses consist of particles that are } \\
\text { separated by relatively large distances }\end{array}$ \\
\hline $\begin{array}{l}\text { Gases can move through each other } \\
\text { rapidly }\end{array}$ & $\begin{array}{l}\text { Gas Particles move in random rapid } \\
\text { straight line motion }\end{array}$ \\
\hline Gases exert pressure & $\begin{array}{l}\text { Gas particle exert no attractive force on } \\
\text { each other }\end{array}$ \\
\hline Pressure of gases depends on temperature & $\begin{array}{l}\text { Gas particles kinetic energy depends on } \\
\text { temperature }\end{array}$ \\
\hline
\end{tabular}

Lesson:

Teacher-led inquiry Demonstration:

1. Discuss what makes a good scientific question and answer.

2. Demonstration: Breaking a ruler with a newspaper on it. Put cheap ruler under news paper. Have portion of ruler hanging over the edge of a desk other part covered by the news paper. Have students hit portion of ruler hanging off of the desk. Cheap ruler should break. Why did it happen? What conclusion can you make?

3. Demonstration: Syringe Power. Have students try to push a stoppered syringe to the bottom. Why can't you do it? What conclusion can you make?

4. Demonstration: Upside down cup of water held in by a note card. Place water into a smooth rimmed cup so it just bubbles over the top. Place note card on top and push out the water (suction). Flip the cup upside down. Water should remain in cup. Why does this happen? What conclusion can you make?

5. Demonstration: Vacuum Sealed Children. Put students in a garbage bag, head out. Put hose of shop vac into the bag and have students cover the end of the hose with their hand so bag does not get sucked into it. Tighten up the top of the garbage bag so it is sealed around the student's neck. Turn the Shop-Vac on and suck the air out of bag. Use knowledge from yesterday to explain why it happened.

6. Demonstration: Imploding Can. Place a small amount of water in the bottom of an aluminum can. Heat the can up on a hot plate. When water is boiling, invert the can and place it in a beaker of cold water. The can should implode on itself. Use knowledge from yesterday to explain why it happened. 
Assignment: Read pg 424 to 426 from "Chemistry Connections to Our Changing World" published by Prentice Hall, and answer these questions in essay form. What is pressure and how is it created at the atomic level? How can you increase or decrease pressure in an open or closed system? List as many ways possible.

Outcomes: To have students understand the basic properties of gases and pressure, and be able to describe how pressure can be increased and decreased in a system.

\section{Day 4: Fountain in Your Face Alternative Assessment (Lab based)}

Objective: The students explain why a fountain phenomena occurs using the properties of gases and Kinetic Molecular Theory Postulates.

\section{Benchmarks:}

C1.1D Identify patterns in data and relate them to theoretical models.

C1.1E Describe a reason for a given conclusion using evidence from an investigation.

C2.2c Explain changes in pressure, volume, and temperature for gases using the kinetic molecular model.

Materials: Erhlenmeyer Flask, one holed stopper, water, and piece of glass tubing.

\begin{tabular}{|l|l|}
\hline Gas Properties & Kinetic Molecular Theory Postulates \\
\hline Gases have mass. & $\begin{array}{l}\text { Gases consist of small particles that have } \\
\text { mass }\end{array}$ \\
\hline Gases fill their containers. & $\begin{array}{l}\text { Gas particles have elastic collisions with } \\
\text { each other and their containers. }\end{array}$ \\
\hline Gases are compressible & $\begin{array}{l}\text { Gasses consist of particles that are } \\
\text { separated by relatively large distances }\end{array}$ \\
\hline $\begin{array}{l}\text { Gases can move through each other } \\
\text { rapidly }\end{array}$ & $\begin{array}{l}\text { Gas Particles move in random rapid } \\
\text { straight line motion }\end{array}$ \\
\hline Gases exert pressure & $\begin{array}{l}\text { Gas particle exert no attractive force on } \\
\text { each other }\end{array}$ \\
\hline Pressure of gases depends on temperature & $\begin{array}{l}\text { Gas particles kinetic energy depends on } \\
\text { temperature }\end{array}$ \\
\hline
\end{tabular}

Lesson:

1. See worksheets and rubrics in Appendix C

Assignment: None all parts are done in class. 
Outcomes: To assess students understanding of the basic properties of gases and kinetic molecular theory, utilize this information to re-teach material if needed.

\section{Day 5 Lesson: Inquiry labs on Boyles and Charles Law}

Objective: To create and write up a short lab experiment determining the relationship between pressure and volume, or temperature and volume of a gas in a closed container. 5 data points must be collected.

\section{Benchmarks:}

C4.5a Provide macroscopic examples, atomic and molecular explanations, and mathematical representations (graphs and equations) for the pressure-volume relationship in gases.

C4.5c Provide macroscopic examples, atomic and molecular explanations, and mathematical representations (graphs and equations) for the temperature-volume relationship in gases.

Materials: Balloons, tape, beaker of ice and water, beaker of water, thermometer, stoppered syringe, stands, hot plate and weights.

\section{Lesson:}

Give each student a balloon, a tape measure, a beaker of ice, a beaker of water, a thermometer, a syringe, stands, weights, etc. The students must come up with a way to show the relationship between pressure and volume or temperature and volume. They must be able to collect 5 data points. At the conclusion of this day the students will need to explain the accuracy of their outcome and how it could be improved the next time it is done. Students must also come up with one more question for study.

Format for write up includes

1. Question: How does pressure relate to volume or how does temperature relate to volume?

2. Hypothesis: If pressure __ , then volume

3. Procedure: If temperature __ then volume

4. Results (Data collected and graphed)

5. Analysis of Graph

6. Conclusion (Is your hypothesis correct explain using data collected)

\section{Assignment: Finish mini-lab write ups}

Outcomes: To determine the relationships between pressure and volume and temperature and volume for gases in closed systems. 


\section{Day 6 Lesson: Boyles, Charles and Gay Lussac's Mathematics Day}

Objective: To use the gas relationships, to calculate a missing pressure, temperature, or volume (Combined Gas Laws).

Benchmarks:

C4.5a Provide macroscopic examples, atomic and molecular explanations, and mathematical representations (graphs and equations) for the pressure-volume relationship in gases.

C4.5b Provide macroscopic examples, atomic and molecular explanations, and mathematical representations (graphs and equations) for the pressure-temperature relationship in gases.

C4.5c Provide macroscopic examples, atomic and molecular explanations, and mathematical representations (graphs and equations) for the temperature-volume relationship in gases.

Materials: Overhead projector and worksheet on Boyles, Charles, Gay-Lussac's and Combined Gas Laws (specific worksheet does not matter).

\section{Lesson:}

1. Review how to do temperature and pressure conversions.

2. Ask the students, what do you multiply a number by to make it bigger? Answer: a fraction larger than 1 . What do you multiply a number by to make it smaller? Answer a fraction less than 1.

3. Discuss the relationship for each of the laws. Boyle's law: Pressure increases Volume decreases. Draw a picture of the graph. Note that it is an inverse relationship. Charles Law: Temperature increases Volume increases. Draw a picture of the graph. Note that it is a direct relationship. Gay Lussac's Law: Temperature increases Pressure increases. Draw a picture of the graph. Note that it is a direct relationship.

4. Show them how to use relationships to solve combined gas law problems.

Starting

Value you are If direct relationship If inverse relationship

Looking for and increase make and increase make

Fraction greater than Fraction less than

One. Visa Versa one. Visa Versa

5. Sample problem

\section{First change Second change}

a. What is the volume of a gas at $2.00 \mathrm{~atm}$ and $200.0 \mathrm{~K}$ if its original volume was $300.0 \mathrm{~L}$ at $.25 \mathrm{~atm}$ and $400.0 \mathrm{~K}$.

\begin{tabular}{l|l|l}
$300.0 \mathrm{~L}$ & $200.0 \mathrm{~K}$ & $.25 \mathrm{~atm}$ \\
\hline & $400.0 \mathrm{~K}$ & $2.00 \mathrm{~atm}$
\end{tabular}




\section{First change}

Temperature decreases

Volume decreases

Fraction less than 1

$[200 / 400=.5]$

\section{Second change}

Pressure increase

Volume decreases

Fraction less than 1

$[.25 / 2.00=.125]$

** I prefer teaching it this way because it forces students to understand the relationship more than memorizing a formula.

5. Do as many problems or samples as needed. Have students come to the front and do some for the class, etc.

6. Work on the homework and move around to help anyone who has problems.

Assignment: Worksheet on temperature and pressure conversions, Combined gas law problems.

Outcomes: Students should be able to do combined gas law problems.

\section{Day 7 Lesson: Ideal Gas Law Mathematics Day}

Objective: To use the ideal gas law relationships, to calculate a missing pressure, temperature, or volume or moles.

\section{Benchmarks:}

C4.5a Provide macroscopic examples, atomic and molecular explanations, and mathematical representations (graphs and equations) for the pressure-volume relationship in gases.

C4.5b Provide macroscopic examples, atomic and molecular explanations, and mathematical representations (graphs and equations) for the pressure-temperature relationship in gases.

C4.5c Provide macroscopic examples, atomic and molecular explanations, and mathematical representations (graphs and equations) for the temperature-volume relationship in gases.

Materials: Overhead projector and worksheet

\section{Lesson:}

1. Review how to do temperature and pressure conversions and the combined gas law.

2. Introduce the formula $\mathrm{PV}=\mathrm{nRT}$, where $\mathrm{R}=8.314 \mathrm{kPa} * \mathrm{~L} / \mathrm{mol}^{*} \mathrm{~K}$ or

$$
\mathrm{R}=.0821 \mathrm{~atm} * \mathrm{~L} / \mathrm{mol}^{*} \mathrm{~K}
$$

**I get students to remember it by calling it the pervert law $(\mathrm{Pv}=\mathrm{nrt}$ when sounded out it sounds like "pervert")

3. Discuss the labels on $\mathrm{R}$ and make sure that all units match the labels in the $\mathrm{R}$ you choose to use. Discuss how to know when to use the Combined or Ideal gas law. 
Answer: combined when the system is changing temperature, pressure or volume. Ideal when there is no change.

4. Do these two problems

a. You fill a rigid cylinder that has a volume of $20.0 \mathrm{~L}$ with nitrogen gas to a final pressure of $2.00^{*} 10^{\wedge} 4 \mathrm{kPa}$ at 28 degrees $\mathrm{C}$. How many moles of nitrogen gas does the cylinder contain?

b. A container contains 1280 moles of methane gas and holds $2.24^{*} 10^{\wedge} 3 \mathrm{~L}$ at a temperature of 42 degrees $\mathrm{C}$. What is the pressure inside the container?

5. Do as many problems or samples as needed. Have students come to the front and do some for the class, etc.

6. Work on the homework and move around to help anyone who has problems.

Assignment: Worksheet on Combined gas law problems and Ideal gas Law problems.

Outcomes: Students should be able to do ideal and combined gas law problems.

\section{Day 8 Lesson: Post-test on Gases}

Objective: To assess what the students learned during the unit.

Benchmarks:

C1.1D Identify patterns in data and relate them to theoretical models.

C1.1E Describe a reason for a given conclusion using evidence from an investigation.

C2.2B Describe the various states of matter in terms of the motion and arrangement of the molecules (atoms) making up the substance.

C2.2c Explain changes in pressure, volume, and temperature for gases using the kinetic molecular model.

C4.5a Provide macroscopic examples, atomic and molecular explanations, and mathematical representations (graphs and equations) for the pressure-volume relationship in gases.

C4.5b Provide macroscopic examples, atomic and molecular explanations, and mathematical representations (graphs and equations) for the pressure-temperature relationship in gases.

C4.5c Provide macroscopic examples, atomic and molecular explanations, and mathematical representations (graphs and equations) for the temperature-volume relationship in gases.

Materials: Posttest on Gases

Lesson:

1. Administer Posttest on Gases.

2. Grade Posttest on gases and compare to pretest. Check for learning of benchmarks during the unit. 
Assignment: None

Outcomes: To determine what the students learned during the Inquiry Unit on Gases.

\section{Day 9 Lesson: Retention Test (2-3 weeks later)}

Objective: To assess retention of what the students learned during the Inquiry Unit on Gases.

Benchmarks:

C1.1D Identify patterns in data and relate them to theoretical models.

C1.1E Describe a reason for a given conclusion using evidence from an investigation.

C2.2B Describe the various states of matter in terms of the motion and arrangement of the molecules (atoms) making up the substance.

C2.2c Explain changes in pressure, volume, and temperature for gases using the kinetic molecular model.

C4.5a Provide macroscopic examples, atomic and molecular explanations, and mathematical representations (graphs and equations) for the pressure-volume relationship in gases.

C4.5b Provide macroscopic examples, atomic and molecular explanations, and mathematical representations (graphs and equations) for the pressure-temperature relationship in gases.

C4.5c Provide macroscopic examples, atomic and molecular explanations, and mathematical representations (graphs and equations) for the temperature-volume relationship in gases.

Materials: Retention test

Lesson:

1. Administer Retention test on Gases.

2. Grade Retention test on gases and compare to same test from previous years class as well as to the post test.

Assignment: None

Outcomes: To determine if the students retained learning during the Inquiry Unit on Gases. 


\section{In your Face!!!! An Assessment on Gas Behavior}

Objective: In this activity you will utilize the 6 properties of gases and pressure to explain phenomena.

Materials needed:

2. $250 \mathrm{~mL}$ Erlenmeyer Flask

3. Single-holed stopper with plastic/glass tubing that reaches into the water

4. Water

Procedure (30 minutes):

1. Place $150 \mathrm{~mL}$ of water into the Erlenmeyer flask

2. Place the tubing through the hole in the stopper, make sure it is at least $1 \mathrm{~cm}$ or more below the water's surface. Stopper the flask.

3. Observation \#1: Observe what is happening at this point. Take notes on your lab sheet. Using diagrams and notes, describe why this observation is happening. Explain using the 6 kinetic properties of gases (as many as apply) and the ideas of pressure to describe what you see.

4. While holding the rubber stopper in place. Blow into the tubing. Keep blowing until you can blow no more.

5. When you can blow now more, quickly remove your face from the tubing. Observe what happens.

6. Observation \#2: Observe what is happening at this point. Take notes on your lab sheet. Using diagrams and notes, describe what happened. Use the 6 kinetic properties of gases (as many as apply) and the ideas of pressure to describe what you see.

7. Observation \#3: When the observed phenomenon stops, observe what is happening now. Take notes on your lab sheet. Using diagrams and notes, explain why it stopped. Make sure to use the 6 kinetic properties of gases (or as many as apply) and the ideas of pressure to describe what you see.

8. Extension: If only the air in the flask above the water could be heated, what would happen to the water in the flask? Using diagrams and notes, as well as the 6 kinetic properties of gases (as many as apply) and the ideas of pressure, to explain your hypothesis. 
Bonus: Describe a real-world situation where this phenomenon could be seen. Explain how and why this phenomenon would occur.

\section{Lab Data Recording Sheet (first 30 minutes of class):}

This paper is used to collect your thoughts as you and your partner discuss the activity and its observations. Be specific and detailed. This is the only sheet you will be allowed to look at when you complete the individual portion of the assessment. I will not be checking this paper. It is for your use only.

\section{Modified Answer Sheet for Quiz (last 30 minutes of class):}

\begin{tabular}{|c|c|c|}
\hline Situation & Diagram & $\begin{array}{l}\text { Explanation of why it happened (utilizing the } 6 \\
\text { kinetic properties of gases and the ideas of } \\
\text { pressure) }\end{array}$ \\
\hline $\begin{array}{l}1 . \\
\text { Observation } \\
\# 1: \text { When the } \\
\text { stopper and } \\
\text { tubing are } \\
\text { placed into } \\
\text { the water. } \\
\text { (NO air is put } \\
\text { in) }\end{array}$ & & \\
\hline $\begin{array}{l}2 . \\
\text { Observation } \\
\# 2 \text { : When the } \\
\text { water is } \\
\text { spurting out. }\end{array}$ & & \\
\hline $\begin{array}{l}3 . \\
\text { Observation } \\
\# 3: \text { When the } \\
\text { fountain } \\
\text { stops. }\end{array}$ & & \\
\hline $\begin{array}{l}\text { 4. Extension: } \\
\text { When only } \\
\text { the air in the } \\
\text { flask above } \\
\text { the water is } \\
\text { heated. }\end{array}$ & & \\
\hline
\end{tabular}




\begin{tabular}{|l|l|l|}
\hline Bonus: & & Answer: \\
& & \\
\hline
\end{tabular}




\section{"In your Face" Fountain Rubric:}

Before air is blown into Erlenmeyer flask

3 points

Criteria:

Describes air molecules in motion above the water creating pressure Describes air molecules filling the space above the water Describes pressures above water being slightly greater than that above the straw so water will rise slightly into the straw

After air is blown into the Erlenmeyer flask

3 points Criteria

Describes more air molecules being placed above the water

Describes more pressure above water due to more molecules/causing more collisions or the gas is compressed into the space

Accounts for water spraying because the pressure inside is greater than pressure outside so water is pushed up the straw

Fountain stopping

3 points

Criteria

Describes the air molecules spreading apart/needing more space

Describes the pressure lowering above the water due to the expansion of the gas molecules

Describes the pressures equalizing between the inside and outside of the flask

Extension: Temperature increase of air above the water

3 points

Criteria

Describes the air molecules above the water as moving faster, causing more collisions and more pressure

Describes the pressure being greater above the water

Describes the greater pressure causing the water to spray out, because there is a difference between the inside and outside pressures

Extra Items to be mentioned in any observation explanation 1 point Describe the air above the water has mass

$\begin{array}{llllll}\text { Before air is blown into Erlenmeyer flask } & 0 & 1 & 2 & 3\end{array}$

$\begin{array}{lllll}\text { After air is blown into Erlenmeyer flask } & 0 & 1 & 2 & 3\end{array}$

$\begin{array}{llllll}\text { Fountain Stopping } & 0 & 1 & 2 & 3\end{array}$

Extension: Temperature increase of air above $\quad \begin{array}{lllll}0 & 1 & 2 & 3\end{array}$

Extra points

$0 \quad 1$

Total $/ 13$ 
Appendix C: Pre- and Post-test on Gas Properties and Gas Law Unit

Gas Law Pretest and Post Test

Define the following words in a sentence

2pts-well defined, with all key pieces of correct information presented

1pt-partially defined, some key pieces of correct information presented

0pts-does not define it correctly or at all

\begin{tabular}{|l|l|}
\hline Word & Definition \\
\hline 1. Boyles Law & \\
\hline 2. Charles Law & \\
\hline $\begin{array}{l}\text { 3. Guy Lussac's } \\
\text { Law }\end{array}$ & \\
\hline $\begin{array}{l}\text { 4. Ideal Gas } \\
\text { Law }\end{array}$ & \\
\hline $\begin{array}{l}\text { 5. Pressure } \\
\text { 6. Temperature }\end{array}$ & \\
\hline 7. Volume & \\
\hline $\begin{array}{l}\text { 8. Kinetic } \\
\text { Molecular } \\
\text { Theory }\end{array}$ & \\
\hline 9. Gas \\
\hline $\begin{array}{l}\text { 10. Scientific } \\
\text { Relationship }\end{array}$
\end{tabular}

11. Recall: What are the three states of matter commonly found of earth?

12. Classifying: Place the following substances under the correct headings:

Ice cube, helium, water, sand, oxygen, mercury, juice, plastic bottle, horse shoe, water vapor

\begin{tabular}{|l|l|l|}
\hline $\begin{array}{l}\text { Molecules tightly packed } \\
\text { Molecules vibrating }\end{array}$ & $\begin{array}{l}\text { Molecules tightly packed } \\
\text { Molecules rolling over each } \\
\text { other }\end{array}$ & $\begin{array}{l}\text { Molecules space out } \\
\text { Molecules bouncing around }\end{array}$ \\
\hline & & \\
\hline
\end{tabular}


Multiple Choice: Circle the response that best answers the question.

13. I left my basketball out during the winter. What is going to happen to the volume of the basketball?
a. Get bigger
b. Get smaller
c. Stay the same

14. In hot air balloons they heat up the air and blow it into the balloon. What is happening to the pressure of the air in the balloon once it is heated? See picture below
a. Getting higher
b. Getting lower
c. Staying the same

15. If I held a balloon in my hands and squeezed so it got smaller. What would happen to the pressure inside the balloon?
a. Get bigger
b. Get smaller
c. Stay the same

16. Which line on the graph represents the relationship between pressure and volume of a gas?
a. Line A
b. Line B
c. Line $\mathrm{C}$

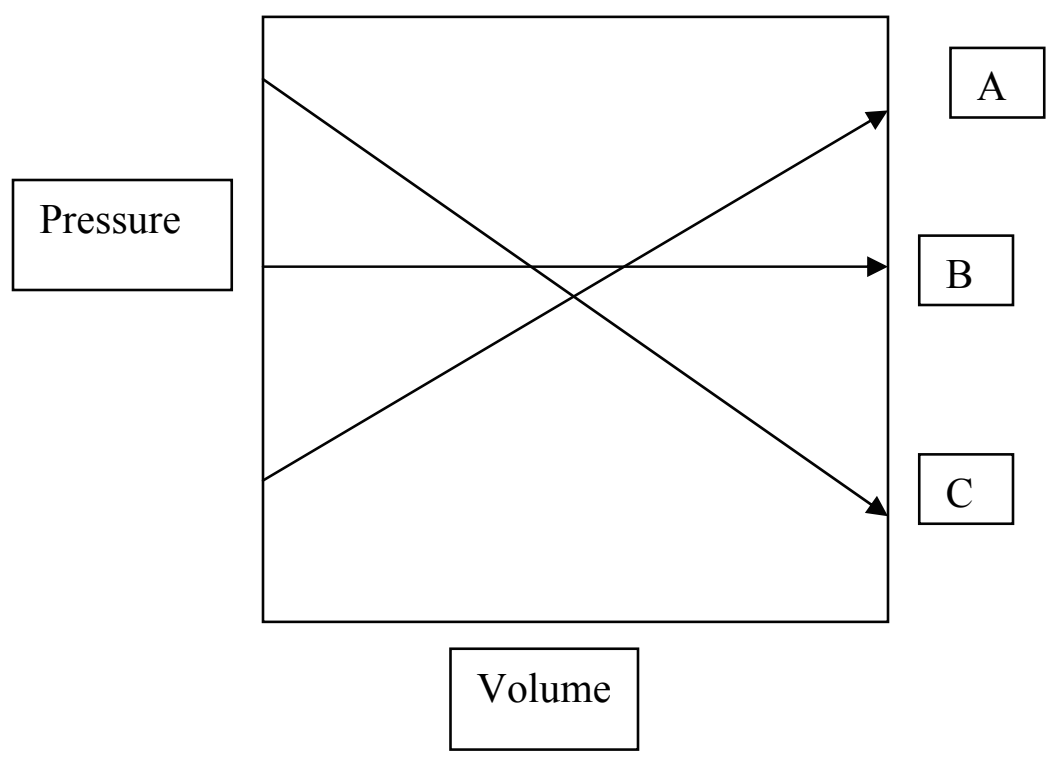


17. Which line on the graph represents the relationship between pressure and Temperature of a gas?
a. Line A
b. Line $\mathrm{B}$
c. Line $\mathrm{C}$

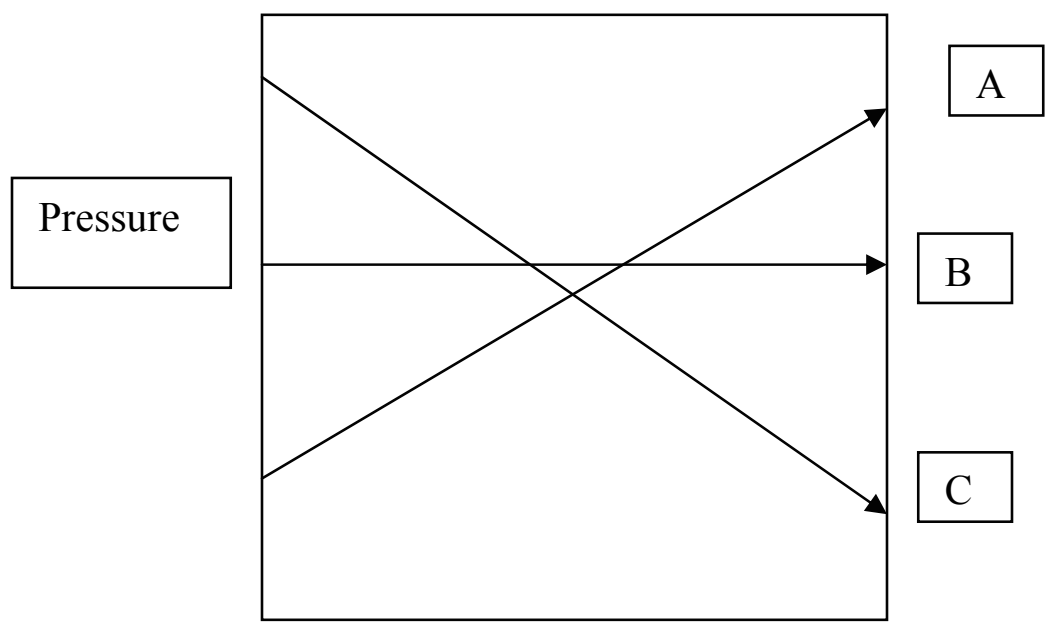

Temperature

18. Which line on the graph represents the relationship between Temperature and volume of a gas?

a. Line $\mathrm{A}$

b. Line $\mathrm{B}$

c. Line $\mathrm{C}$

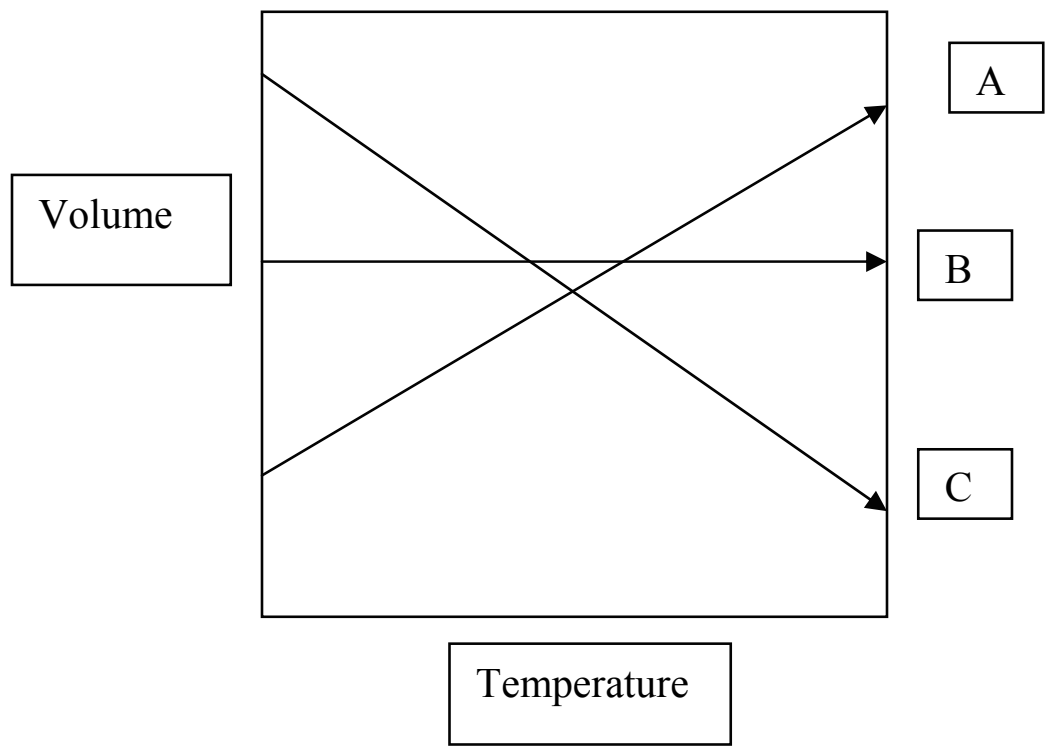

19. If a have a balloon filled with a set amount of gas. No gas can escape. Each circle represents a molecule of the gas. 


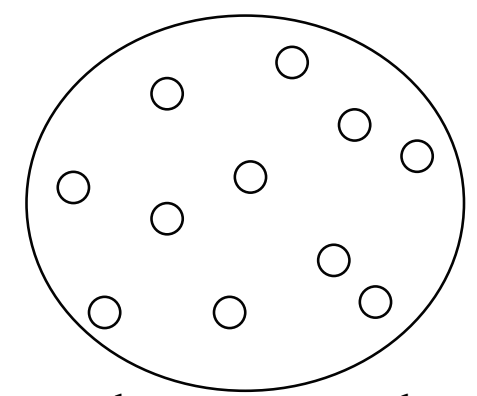

a. What would happen to the movement and arrangement of the particles if I increased the pressure? What would happen to temperature and volume? Explain using molecules on the atomic level. Draw a model of it in the circle below, use circles to represent the molecules.

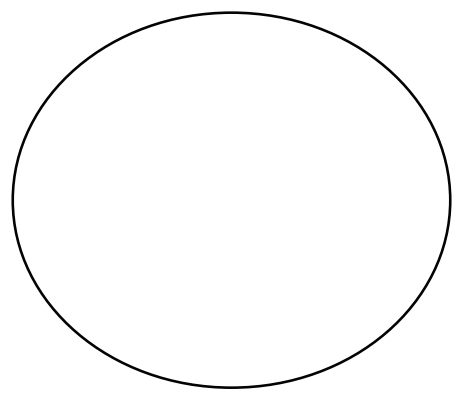

Temperature explanation

Volume explanation

b. What would happen to the movement and arrangement of the particles if I decrease the volume? What would happen to temperature and pressure? Explain using molecules on the atomic level. Draw a model of it in the circle below, use circles two represent the molecules.

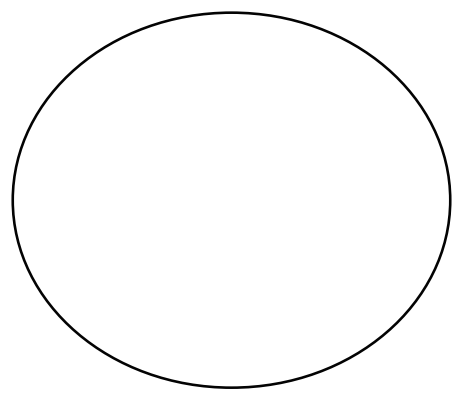

Temperature explanation

Pressure explanation

c. What would happen to the movement and arrangement of the particles if I decrease the temperature? What would happen to volume and pressure? Explain using molecules on the atomic level. Draw a model of it in the circle below, use circles two represent the molecules.

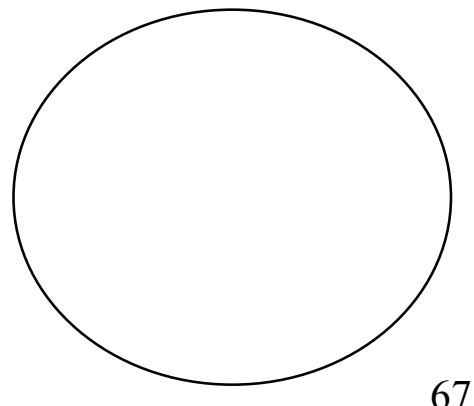

Volume explanation

Pressure explanation 


\section{Math Problems}

Scoring guide: 2 points for the correct work leading to the answer/deductions for missing steps

3 points for the correct answer (all or none)

1 points for the correct label on the answer.

1 point for the correct significant figures on the answer

20. If you are given a canister of a gas (no molecules can escape) at a pressure of $23.0 \mathrm{~atm}$., a volume of $500 \mathrm{~L}$, and a temperature of 32 degrees Celsius, what would the volume be if the pressure was decreased to $5 \mathrm{~atm}$. and temperature was raised to 100 degrees Celsius?

21. I have another canister of gas at a pressure of $5.23 \mathrm{~atm}$. and a volume of $42.7 \mathrm{~L}$. If the temperature is 78 degrees Celsius, how many moles of gas are in the container? 


\section{Appendix D: Retention Test on Gas Properties and Gas Laws}

Gas Law Test with Enthalpy and Review Problems

1. Define the following terms accurately and with detail. Make sure to show that you have a solid understanding of the word

\begin{tabular}{|l|l|}
\hline Word & Definition \\
\hline Boyle's Law & \\
\hline Charles' Law & \\
\hline $\begin{array}{l}\text { Gay-Lusaac's } \\
\text { Law }\end{array}$ & \\
\hline Ideal Gas Law & \\
\hline n & \\
\hline P & \\
\hline V & \\
\hline T
\end{tabular}

2. Name the 6 properties of gases and describe how Kinetic Molecular Theory explains them.

3. What is ....

Standard Temperature

Standard Pressure

The volume of gas at STP

4. Perform the following conversions

380 Torr to $\mathrm{mmHg}$

$2.5 \mathrm{~atm}$ to torr

$27^{\circ} \mathrm{C}$ to Kelvin

$550 \mathrm{~mL}$ to $\mathrm{L}$

5. Calculate

a. A gas at 1000 torr occupies $1.5 \mathrm{~L}$. At what pressure will the gas occupy 3.0 L if the temperature remains unchanged? 
b. A sample of gas at STP. What will the temperature be after the pressure is increased to 950 torr?

c. A gas with unknown volume at $250 \mathrm{~K}$ and $350 \mathrm{mmHg}$ is changed to $300 \mathrm{~K}$ and $250 \mathrm{mmHg}$. If the new volume is $1000 \mathrm{~mL}$, what was the old volume?

d. A $2500 \mathrm{~mL}$ sample of gas at $30^{\circ} \mathrm{C}$ is heated and expands to a volume of $3500 \mathrm{~mL}$ at constant pressure. What temperature was required to do this?

6. What volume will 2.0 moles of nitrogen occupy at 720 torr and $20^{\circ} \mathrm{C}$ ?

7. How many moles of oxygen will occupy a volume of 2.5 liters at $1.2 \mathrm{~atm}$ and $25^{\circ} \mathrm{C}$ ?

8. A can villed with air is heated to force some of the air out of the can. When the can is capped and cooled it will crush because the pressure inside has surface. due to molecules colliding against the
a. increased $/$ more
b. decresded/more
c. increased/fewer
d. decreased/fewer

9. A car tire is inflated to a pressure of 32 pounds per square inch. The reason the pressure can be measured is due to the
a. collision of air molecules with the sides of the tire.
b. Air molecules leaking out of the rubber
c. The diffusion of air with the rubber
d. Sinking of air molecules to the bottom of the tire.

10. Gas pressure can be measured on the surface because gas molecules will
a. float
b. collide
c. mix
d. diffuse

11. The diffusion of one gas into another is due to the

a. gas molecules having similar charges

b. gases combining to make new compounds 
c. constant random motion of the gas molecules

d. high temperatures of the two gases

12. A bottle of sweet smelling ester was opened and in a short period of time the ester smell was detected across the room. This is due to the odor molecules

a. being heavier than the air molecules and sinking to the floor

b. being lighter than the air molecules and rising to the ceiling

c. moving from low concentration to high concentration

d. moving randomly and diffusing across the room

13. As molecules collide with the surface of a container, they create
a. density
b. potential energy
c. pressure
d. mass

14. You are working on an experiment which must be conducted under conditions of standard temperature and pressure. If the room temperature is $25 \mathrm{oC}$ and the pressure is $750 \mathrm{mmHg}$ then the experiment must be conducted
a. in that room
b. in a cooler, lower pressure container than that room
c. in a warmer, higher pressure container than that room
d. in a cooler higher pressure container than that room.

15. A weather balloon is inflated to $2.0 \mathrm{~L}$ and a pressure of $1.0 \mathrm{~atm}$, at sea level. The balloon is released and allowed to increase in altitude, where the air pressure is less. Assuming no change in temperature, which correctly explains the change in volume for the balloon?

a. An increase in volume due to more air molecules inside the balloon

b. An increase in volume due to the lowered pressure pushing inward on the balloon

c. A decrease in volume due to a decrease in force being exerted upon it from the atmosphere

d. A decrease in volume due to fewer air molecules inside the balloon.

16. What is the temperature under the condition referred to as STP?
a. $0 \mathrm{~K}$
b. $273 \mathrm{~K}$
c. $273^{\circ} \mathrm{C}$
d. $546^{\circ} \mathrm{C}$ 
17. A balloon at $1.00 \mathrm{~atm}, 27^{\circ} \mathrm{C}$ holds $12.0 \mathrm{~L}$ of gas. The balloon is submerged in a liquid such that the pressure is $1.50 \mathrm{~atm}$ and the volume drops to $4.00 \mathrm{~L}$. What is the temperature of the balloon?
a. $50 \mathrm{~K}$
b. $150 \mathrm{~K}$
c. $300 \mathrm{~K}$
d. $600 \mathrm{~K}$

18. A balloon at $100.0 \mathrm{~L}$ at $1.00 \mathrm{~atm}$ and $27^{\circ} \mathrm{C}$. The balloon rises to an altitude of $10000 \mathrm{~m}$ where the temperature is $150.0 \mathrm{~K}$ and the pressure is $.500 \mathrm{~atm}$.. What is the volume of the balloon?
a. $25.0 \mathrm{~L}$
b. $50.0 \mathrm{~L}$
c. $100 . \mathrm{L}$
d. 200. L

19. At what temperature does 5.00 moles of oxygen occupy $22.4 \mathrm{~L}$ if the atmospheric pressure is $1.00 \mathrm{~atm}$ ?
a. $54.6 \mathrm{~K}$
b. $109 \mathrm{~K}$
c. $328 \mathrm{~K}$
d. $382 \mathrm{~K}$

20. During which portion of the graph is a phase change occurring?

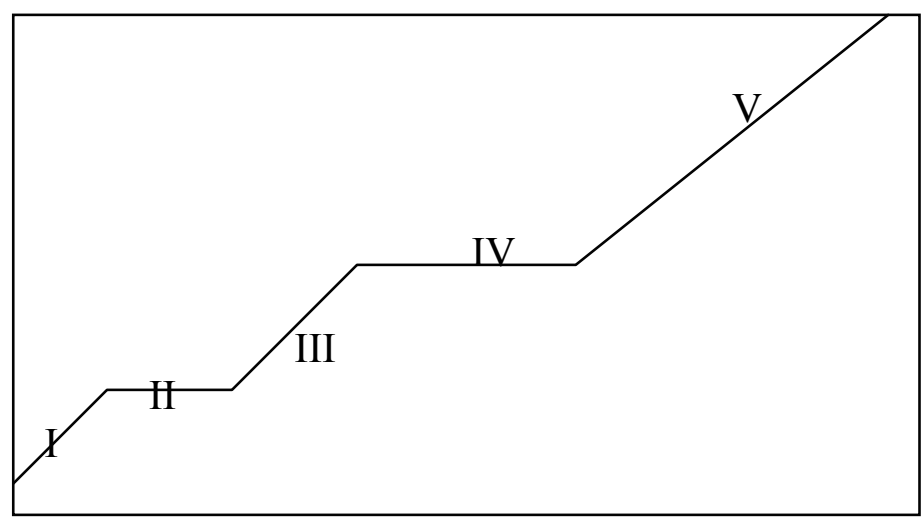
a. I and III
b. I, II, and III
c. II and IV
d. III, IV, and V

21. In order to change Celsius into Kelvin you must

a. Add 100 to the Celsius

b. Subtract 100 from the Celsius

c. Add 273 to Celsius 


\section{d. Subtract 273 from Celsius}

22. The molecular mass of $\mathrm{Na}_{2} \mathrm{CO}_{3}$ is
a. 51 grams
b. 74 grams
c. 106 grams
d. 153 grams

23. What is the volume in liters of 2 moles of carbon dioxide at STP?
a. $.089 \mathrm{~L}$
b. $11.2 \mathrm{~L}$
c. $44.8 \mathrm{~L}$
d. $12.04 \times 10^{23} \mathrm{~L}$ 


\section{Appendix E: Student Attitude Survey}

Attitude Survey for Chemistry Gas Law Inquiry Unit

Date:

Grade level

Gender (circle one) Male

Female

In two sentences what are the key pieces of scientific information that you learned today?

What scientific skills did you have to use today to complete the lesson/activity?

Respond to each question

\begin{tabular}{|c|c|c|c|c|c|c|c|c|}
\hline $\begin{array}{l}\text { Quest. } \\
\text { \# }\end{array}$ & Statement & $\begin{array}{l}\text { Str } \\
\text { Str } \\
\mathrm{Ag}\end{array}$ & $\begin{array}{l}\text { nse } \\
\text { ly } \\
\text { fy I }\end{array}$ & igre & eut & & & \\
\hline 1 & $\begin{array}{l}\text { I understand the material we are } \\
\text { learning in class today }\end{array}$ & -3 & -2 & -1 & 0 & 1 & 2 & 3 \\
\hline 2 & $\begin{array}{l}\text { I could teach the material I learned } \\
\text { today to someone else. }\end{array}$ & -3 & -2 & -1 & 0 & 1 & 2 & 3 \\
\hline 3 & $\begin{array}{l}\text { I enjoyed the lesson that was taught } \\
\text { today. }\end{array}$ & -3 & -2 & -1 & 0 & 1 & 2 & 3 \\
\hline 4 & $\begin{array}{l}\text { I thought the teacher explained the } \\
\text { content/directions well today. }\end{array}$ & -3 & -2 & -1 & 0 & 1 & 2 & 3 \\
\hline 5 & $\begin{array}{l}\text { I would like do learn more about the } \\
\text { material that was taught today. }\end{array}$ & -3 & -2 & -1 & 0 & 1 & 2 & 3 \\
\hline 6 & $\begin{array}{l}\text { I felt there was enough time to } \\
\text { complete the activities today. }\end{array}$ & -3 & -2 & -1 & 0 & 1 & 2 & 3 \\
\hline 7 & $\begin{array}{l}\text { I felt prepared to do what was } \\
\text { expected of me today. }\end{array}$ & -3 & -2 & -1 & 0 & 1 & 2 & 3 \\
\hline 8 & $\begin{array}{l}\text { I put my full effort into what was } \\
\text { expected of me today. }\end{array}$ & -3 & -2 & -1 & 0 & 1 & 2 & 3 \\
\hline 9 & $\begin{array}{l}\text { I liked working with my } \\
\text { partner/group today. }\end{array}$ & -3 & -2 & -1 & 0 & 1 & 2 & 3 \\
\hline 10 & $\begin{array}{l}\text { I feel I could do well on a test over } \\
\text { this material if given it today. }\end{array}$ & -3 & -2 & -1 & 0 & 1 & 2 & 3 \\
\hline
\end{tabular}

Comments on any question above please put the number of the question along with your comment 